\title{
Peptide YY: a novel Paneth cell antimicrobial peptide that maintains fungal commensalism
}

\section{Joseph F. Pierre', Diana La Torre', Ashley Sidebottom ${ }^{1}$, Amal Kambal ${ }^{1}$, Xiaorong Zhu ${ }^{1}$, Yun Tao ${ }^{1}$, Candace M. Cham ${ }^{1}$, Ling Wang ${ }^{1}$, Katharine G. Harris ${ }^{1}$, Olga Zaborina ${ }^{3}$, John Alverdy $^{3}$, Herbert Herzog ${ }^{4}$, Jessica Witchley $^{2}$, Suzanne M. Noble ${ }^{2}$, Vanessa Leone ${ }^{1}$, Eugene B. Chang ${ }^{1}$}

${ }^{1}$ Department of Medicine, University of Chicago, Chicago, IL, USA

${ }^{2}$ Department of Microbiology and Immunology, School of Medicine, University of California San Francisco, San Francisco, CA, USA

${ }^{3}$ Department of Surgery, University of Chicago, Chicago, IL, USA

${ }^{4}$ Garvan Institute of Medical Research, Sydney, Australia

\section{Corresponding Author:}

Eugene B. Chang, MD

Martin Boyer Professor of Medicine

Department of Medicine

Knapp Center for Biomedical Discovery

University of Chicago,

Chicago, IL

\section{SUMMARY}

Perturbed interactions between the intestinal microbes and host correlate with emergence of fungal virulence. Here we report a previously unknown role for peptide YY (PYY), a described endocrine molecule, as an antimicrobial peptide (AMP) expressed by gut immune epithelial Paneth Cells (PC). PC-PYY differs from other AMPs, including lysozyme, because of limited antibacterial activity, packaging in discrete secretory granules, and selective antifungal activity to virulent hyphae, but not yeast forms of Candida albicans. The latter action is through binding of cationic PC-PYY to the anionic hyphal surface, resulting in membrane disruption and killing. PC-PYY is compartmentalized to surface mucus, which optimizes activity and prevents conversion to endocrine PYY by dipeptidyl peptidase-IV (DPP-IV). We conclude PC-PYY is a unique AMP with selective antifungal activity that maintains gut fungal commensalism. Compromised PC-PYY action from PC dysfunction and/or mucus depletion in ileal Crohn's disease may initiate or contribute to disease via fungal pathogenesis.

Key words: Innate immunity, antimicrobial peptide, antifungal, fungal virulence, gut mycobiome, mucus, mucosal barrier, commensalism, inflammatory bowel diseases, Crohn's Disease

\section{Highlights:}


? Paneth Cell PYY (PC-PYY) is an antimicrobial peptide that differs from endocrine-PYY

? PC-PYY is a selective anti-fungal peptide, targeting the virulent form of C. albicans

? PC-PYY is separately packaged, retained by mucus, and released by C. albicans hyphae

? PC-PYY is proposed as essential for maintenance of fungal commensalism in the gut

\section{INTRODUCTION}

The coevolution of metazoans and microbes has been paramount to the development of mutualistic beneficial relationships, particularly in the digestive tract where trillions of microbes form region-specific stable and resilient microbial communities essential for processes such as immune and metabolic development and intestinal homeostasis (Costello et al., 2009; Lee et al., 2013; Rakoff-Nahoum et al., 2004). While much of this knowledge has been gained through studies of the Bacteria domain, other microbes such as Fungi and Archaea cohabitate this space. Collectively, these microbes are carefully selected and "tolerated" by the host. This being said, far less is known about how these populations are surveyed and maintained by the host. For fungi, several studies have identified innate immune pathways such as C-type lectins, including Dectin-1 and the mannose receptor, that deter systemic infection through activation of the immune system (Iliev et al., 2012), but their role and actions in deterring fungal infection are not specific and can ultimately cause collateral damage to host cells and other members of the gut microbiome.

Although peptide YY (PYY) is best known as a satiety hormone secreted by enteroendocrine cells (EECs), we now report that PYY is expressed by innate immune Paneth cells of the gut where it appears to be a unique antimicrobial peptide (AMP) with selective activity against the virulent form of polymorphic Candida albicans. C. albicans is a commensal yeast of the gastrointestinal tract, but it is also an opportunistic pathogen commonly seen to cause disease in immunocompromised patients (Hoarau et al., 2016; Sokol et al., 2017b). PYY is a highly conserved 36-amino acid peptide produced by diverse vertebrate species that range from cartilaginous fish to humans (Conlon, 2002). Since its discovery in porcine intestine and brain in 1982, PYY has been shown to regulate energy homeostasis and food intake, sympathetic vascular tone, digestion, circadian rhythms, and other endocrine and autonomic functions (Tatemoto, 1982; Batterham et al., 2006; Glavas et al., 2008; Hill et al., 2011; Holzer, 2016). These classically understood endocrine functions of PYY are mediated by the binding of the dipeptidyl peptidase IV (DPP-IV)-modified form of PYY, PYY 3 -36, to the neuropeptide Y receptor (Y2), to which the unmodified form, $\mathrm{PYY}_{1-36}$, poorly binds (Batterham et al., 2002; Grandt et al., 1994; Keire et al., 2000). Until our report, intestinal PYY was thought to have solely an endocrine function, released postprandially into the blood circulation by EECs to activate many regions of the brain important to the control of behavior and satiety.

\section{RESULTS}




\section{PYY is expressed by intestinal innate immune Paneth cells primarily found in the murine and human distal ileal mucosa}

While visualizing L-cells in sectioned murine distal ileum by staining PYY with fluorescence antibodies or fluorescence in situ hybridization (FISH), we made the serendipitous discovery that PYY is also present in cells expressing lysozyme, a classical marker of Paneth cells (Figures 1A and 1B). This unanticipated and previously unreported finding was perplexing, as Paneth cells are innate immune epithelial cells of the gut mucosa known to express and secrete AMPs that defend against pathogens and shape the regional gut microbiome. We also confirmed that PYY immunolocalized to Paneth cells in ileal mucosal biopsies from healthy human adults (Figure S1A). We determined that the immunoreactivity was specific to PYY in Paneth cells by using primary antibody pre-adsorbed with recombinant PYY, which resulted in nearly complete quenching of signal from both L- and Paneth cells (Figure S1B). Additional confirmation was made through high resolution images obtained by stimulated emission depletion (STED) microscopy, which revealed that PYY and lysozyme appear to be packaged into discrete granules (Figures 1C and S2), raising the possibility that they might have different roles, sorting pathways, and regulation (Clevers and Bevins, 2013). To further verify that PYY is produced in Paneth cells, laser capture micro-dissection was performed on sections of the murine ileum to isolate distinct populations of basal crypt cells which would include Paneth cells, and villus tip cells where mature L-cells are found (Figure 1D). Confirmation of distinct villus and base crypt populations was conducted by detection of transcripts of Paneth cell (cryptidin 1), and villus cell (sucrase-isomaltase) markers (Figure 1E), respectively. Quantitative RT-PCR was then performed on total RNA extracted from these populations, revealing robust PYY transcript levels in the basal crypt population in line with other Paneth cell-specific AMP transcripts. Finally, we utilized publicly available databases of single cell RNAseq from murine small intestinal epithelial cells. We identified PYY expression in mature enteroendocrine populations through the marker genes Secretogranin-1, CCK, and GLP1, but also in Paneth cell populations defined by the marker genes Cryptdin 17, ATG16L1, DEFAA5, and Lysozyme. (Figures S3A and S3B) (Haber et al., 2017).

PYY is a Paneth cell antimicrobial peptide that has limited anti-bacterial activity, but selectively targets virulent, but not commensal Candida albicans

The expression of PYY in intestinal Paneth cells, which secretes AMPs into the gut lumen, suggested an alternative antimicrobial function. As many AMPs have previously described broad activity against bacterial species, we assessed the activity of synthesized PYY peptide (amino acids 1-36) for anti-bacterial activity against a panel of representative grampositive and -negative strains. PYY did have significant, but limited effects on in vitro viability and proliferation of some Gram positive microbes such as Lactobacillus rhamnosus, Enterococcus faecalis, Listeria monocytogenes, and Gram negative Escherichia coli, Bacteroides fragilis, but in other cases there was no antimicrobial activity observed, including 
Peptostreptococcus anaerobius, Staphylococcus aureus, Salmonella enterica, and Pseudomonas aeruginosa (Figures 2A, 2B and S4). Overall, the anti-bacterial activity of PYY was underwhelming compared to that of other AMPs (e.g., magainin-2, an amphibian analog of PYY, see below) (Figures 2A and 2B). This was surprising because the predicted structure of PYY bears striking resemblance to another alpha-helical, amphipathic AMP, the amphibian analog magainin-2 (Figures 2C and 2D). Magainin-2 is produced in the skin of the African clawed frog (Xenopus laevis) where it has a wide spectrum of antimicrobial activity against many species of bacteria and fungi. Because fungi were not included in our initial screen, we then tested the activity of PYY against C. albicans (Figure 3). Candida species can exist in a commensal yeast state or a virulent multicellular, filamentous hyphal form that includes altered gene expression and functional properties, the latter including mucosal invasion, immune activation, and inflammation (Moyes et al., 2010; Noble et al., 2017)

We therefore investigated the effect of PC-PYY (herein also specified as PYY $1-36$ ) on $C$. albicans growth and viability. As will be shown later, PC-PYY is strictly the unmodified, full length $\mathrm{PYY}_{1-36}$, whereas the endocrine form is primarily the $\mathrm{PYY}_{3-36}$ form. We used liquid culture conditions which promote the growth of the yeast or hyphal forms of $C$. albicans. Yeast extract Peptone Dextrose (YPD) broth was used to promote yeast growth and RPMI 1640 was used for induction of hyphal growth (Mukaremera et al., 2017; Weerasekera et al., 2016). Additionally, $2.5 \% \mathrm{w} / \mathrm{v}$ porcine mucin (mucus) was included in growth media to investigate environment driven bioactivity within the gut. To determine whether PYY $Y_{1-36}$ permeabilizes virulent $C$. albicans hyphae, we exposed $\mathrm{PYY}_{1-36}$-treated hyphae to propidium iodide (PI), a dye that is excluded from cells with intact plasma membranes and fluorescently labels DNA upon

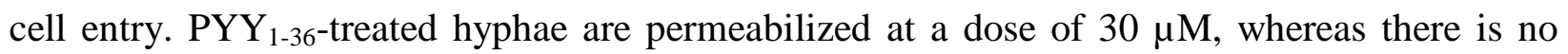
effect on the yeast form, indicating hyphae-specific bioactivity (Figure 3A). PYY 1-36 was tested in other species of Candida, including C. tropicalis and C. dubliniensis, where both were susceptible, but the latter was more difficult to assess as the broth conditions were not optimal for yeast to hyphae conversion (data not shown). $\mathrm{PYY}_{1-36}$ - fluorescein isothiocyanate (FITC) tagged peptide localizes to the same region of the hyphae that shows PI penetration into the cytoplasm, consistent with direct permeabilization as a mechanism of action.

We further tested the effect of PYY ${ }_{1-36}$ on the viability of $C$. albicans by subjecting both the hyphae and yeast forms to increasing concentrations of $\mathrm{PYY}_{1-36}$ in growth media with 2.5\% w/v mucus (the natural environment for PC-PYY as will be shown below). PYY 1-36 $_{\text {showed no }}$ effect on yeast viability, as measured with CFUs, but did show significant hyphae death measured with XTT viability in both standard buffer and $2.5 \% \mathrm{w} / \mathrm{v}$ mucus (Figures 3B, 3D and S5). On the other hand, the enteroendocrine form $\mathrm{PYY}_{3-36}$ had much less impact on hyphae (Figure S5). The effect of PYY ${ }_{1-36}$ on yeast and hyphae growth was assessed by exposing the two forms in their respective growth media to increasing concentrations of PYY 1 -36, optical density measurements were used for yeast while dry weight measurements were used for hyphae to account for the different properties of the two forms. Again, yeast showed no decrease in growth regardless of $\mathrm{PYY}_{1-36}$ concentration, whereas hyphae showed significant growth reduction from 
$20-50 \mu \mathrm{M}$ (Figures $3 \mathrm{C}$ and $3 \mathrm{E}$ ). It is notable that the dose-response of PYY $\mathrm{P}_{1-36}$ action in aqueous (RPMI) buffer is biphasic in functional assays, where the peak effect is $\sim 30 \mu \mathrm{M}$ with progressive loss of activity by $100 \mu \mathrm{M}$. Similar biphasic responses have been reported for other AMPs (Kagan et al., 1994; Phadke et al., 2002), which we attribute to concentration-dependent selfaggregation or multimerization of amphipathic alpha-helical AMPs in aqueous buffer, resulting in decreased bioactivity and bioavailability. Supporting this notion, a typical sigmoidal doseresponse curve is seen when the assay is performed in $2.5 \% \mathrm{w} / \mathrm{v}$ mucus (Figures $3 \mathrm{E}$ and $3 \mathrm{~F}$ ). We posit that mucus has properties that prevent self-aggregation of $\mathrm{PYY}_{1-36}$ and is the natural environment for PC-PYY that confers optimal activity, retention, and stability (see below), which was supported by luminal vs mucosal mass spectrometry quantification of PYY described below.

As we had observed inhibition of growth and decreased viability of the hyphal, but not

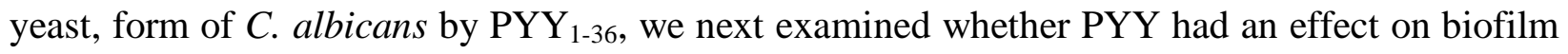
formation. Hyphal morphogenesis is essential not only for $C$. albicans virulence, but is also required for the establishment of biofilms, which are structured communities of yeasts and hyphae that form on surfaces such as denture material or intravenous catheters. Biofilms promote and exacerbate disease at mucosal surfaces by serving as a source for fungal dissemination and intrinsic resistance to antimicrobial agents. Using in vitro assays for biofilm formation that quantitate biofilm by crystal violet staining, we show that PYY ${ }_{1-36}$ in RPMI with or without $2.5 \%$ w/v mucus and magainin-2, but not a scrambled peptide control disrupts this clinically significant virulence attribute (Figure $3 \mathrm{E}$ and 3F). Again, a classic sigmoidal dose-response curve was observed only when mucus was present.

We next examined the underlying basis for this selectivity for the hyphae form of $C$. albicans. PYY ${ }_{1-36}$ is a cationic, amphipathic alpha-helical peptide with a beta turn and localized negative and positive electrostatic cloud patterns at its surface (Figures 2C and 2D). Other AMPs sharing these structural features are believed to preferentially bind to the anionic surface charge of microbes that then positions the peptide for disruption or pore formation of the lipid membrane that kills or compromises fitness of the microbe (Clevers and Bevins, 2013; van der Weerden et al., 2013). On the other hand, mammalian host cells that have neutral surface charge properties are unaffected by these types of AMPs (Mahlapuu et al., 2016). Using a cationic ferritin probe that identifies anionic surface charge of cell membranes through transmission electron microscopy (TEM), we observed a dramatic difference in surface charge of yeast and hyphae membranes (Figure 4A). Hyphae membranes were found to be anionic, as they were decorated with the cationic probe on their outer surface, whereas the yeast membranes lacked any labeling. Using the same preparation, scanning electron microscopy (SEM) of these two states of $C$. albicans was performed and showed that exposure of $C$. albicans hyphae membranes to $\mathrm{PYY}_{1-36}$ was associated with surface blebbing and irregularities, as opposed to the yeast membranes that appeared unaffected (Figure 4B).

In summary, using five different assay approaches (biofilm formation, propidium iodide uptake, CFU counts, metabolic respiration (XTT), TEM and SEM), we confirm that PYY ${ }_{1-36}$ has 
selective antimicrobial activity against $C$. albicans, preferentially inhibiting growth and/or killing the hyphal form with little or no activity against the yeast form.

\section{Paneth Cell PYY (PYY 1-36): A unique AMP different from Endocrine-PYY (PYY 3-36)}

A hallmark of Paneth cells, which are localized deep in intestinal crypts, is their vectoral secretion of secretory contents such as AMPs into the gut lumen in response to microbial products (Clevers and Bevins, 2013). This is in contrast to PYY of enteroendocrine L-cells that are found in the upper mucosal layers where they secrete PYY and other hormones into mucosal capillaries following food consumption. Although the same PYY1-36 form produced by Paneth cells is initial secreted by L-cells, it is rapidly converted by the ubiquitous dipeptidyl peptidaseIV (DPP-IV) to PYY 3 -36, the major circulating endocrine form that binds to the Y2 receptor to mediate PYY's postprandial endocrine actions (Keire et al., 2010). To examine whether PC-PYY is similar to other PC AMPs in route of action, we used an ex vivo preparation where the murine distal ileum is excised, flushed and ligated at both ends, filled with growth media, and maintained at $37{ }^{\circ} \mathrm{C}$ (Figure S6). PYY ${ }_{1-36}$ was detected by LC-MS (Figure S7) from the luminal compartment (L), overlying surface mucus (M), and mucosal tissue (T) under basal (no treatment) and treatment conditions, after the mucosa was exposed for 2 hours to $C$. albicans yeast, hyphae, or their respective conditioned media (Figure 5A). Minimal PYY $Y_{1-36}$ was detected in the luminal (L), overlying mucus (M), and mucosal tissue (T) of ex vivo intestinal loops under basal conditions. However, in the presence of $C$. albicans hyphae, but not with yeast or conditioned media from either forms, $\mathrm{PYY}_{1-36}$ levels in the mucus compartment increased significantly, whereas no $\mathrm{PYY}_{1-36}$ was detectable in luminal compartment under any of the stimulation conditions. Moreover, $\mathrm{PYY}_{3-36}$ was not detected in any of the samples, a finding similar to a previous report in rat ileum where $\mathrm{PYY}_{1-36}$ was the dominant luminal form (Greeley et al., 1987; Keire et al., 2010). These findings suggested that the PC-PYY is released in response only to the virulent (hyphae) form of $C$. albicans into the overlying mucus where it is retained. As little PYY $\mathrm{PY}_{36}$ was detected in tissue, we speculate that it either rapidly disseminated into the blood circulation or was lost during the tissue preparation procedure. We then explored the possibility that PYY ${ }_{1-36}$, because of its cationic amphipathic properties, has proclivity for the hydrogel properties of mucus. An in vitro phase-transition partitioning experiment was performed where mucus and aqueous compartments were separated by a $10 \mathrm{kDa}$ MWCO filter (Figure 5B). Regardless of whether the initial placement of PYY $Y_{1-36}$ was in the mucus or aqueous compartment, it preferentially partitioned into the mucus compartment, providing a plausible explanation as to why $\mathrm{PYY}_{1-36}$ is retained in mucus. What remained unexplained, however, was why PYY $1-36$, and not PYY $_{3-36}$ is readily detected in overlying mucus where DPP-IV is present (Darmoul et al., 1994; Michel et al., 2008), a finding we confirmed by immunofluorescence (IF)

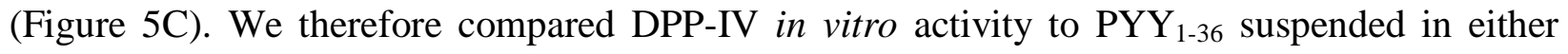
aqueous buffer or porcine gastric mucus, assessing the potential resulting PYY products with LC-MS (Figure 5D). In aqueous buffer, DPP-IV converted PYY $\mathrm{PY}_{1-36}$ to $\mathrm{PYY}_{3-36}$, and no other proteolytic products were found. However, when performed in mucus, $\mathrm{PYY}_{1-36}$ did not undergo 
DPP-IV proteolysis, suggesting the polypeptide arm of PYY may facilitate mucin binding and therefore be protected from proteolytic cleavage. Alternatively, mucus could be decreasing DPPIV enzymatic efficiency. Collectively, these data show that secretion of PC-PYY (PYY $\left.{ }_{1-36}\right)$ is preferentially triggered by $C$. albicans hyphae into overlying mucus where it is retained and protected from enzymatic conversion to $\mathrm{PYY}_{3-36}$ by DPP-IV, allowing it to function as a unique AMP. These properties and regional compartmentalization could well fortify innate mucus defenses against $C$. albicans hyphae, while not affecting commensal yeast forms or other members of the gut microbiota outside of the mucus barrier and in the lumen.

\section{In vivo and in vitro actions of $\mathrm{PY} \mathrm{Y}_{1-36}$ on Candida albicans}

We next sought to further determine the correlation of the above findings to human and murine physiology and pathophysiology. To simulate an intestinal environment, we used human colonic epithelial Caco-2 cells that form monolayers and are able to produce mucus. GFPtagged $C$. albicans grown in a hyphal form were plated over these cells and exposed to PYY $\mathrm{Y}_{1-36}$. The number of attached hyphae were significantly reduced after 4 hours in the presence of PYY ${ }_{36}$ (Figures 6A and 6B). To determine the impact of PYY on fungal populations in vivo, we utilized a mouse model of chronic intestinal colonization in which $C$. albicans persists in the gut lumen and the host remains healthy. The mouse model uses specific pathogen free wild-type (WT) or $\mathrm{PYY}^{-/}$gene-deficient mice on the C57B1/6 background. Oral gavage of colonized animals with PYY ${ }_{1-36}$ decreased fungal titers in stool (Figure 6C). Conversely, the rate of fungal colonization in PYY deficient (PYY-KO) mice was more rapid, achieving a level 2-3-fold higher than in wild type control animals (Figure 6D). Of note, total fecal output remained similar in untreated, PYY-treated, and PYY-KO mice, arguing against changes in the rate of fungal excretion as a determinant of fungal load.

Given the evidence that PC-PYY localizes to the mucus layer and may specifically modulate fungal colonization within this compartment, we next isolated luminal and mucosal associated samples from PYY-KO and WT animals to sequence the internal transcribed spacer (ITS) region. Compared with luminal fungal communities that likely carry more environmentally ingested fungi, the mucus associated layer harbored a distinct fungal population as assessed by Jaccard dissimilarity on principal coordinate analysis (Figure 6E). Within the mucus, PYY-KO animals displayed elevated colonization of Candida and its family, Saccharomycetaceae, along with Saccharomycetaceae, compared with WT animals (Figures 7F-H). In contrast, 16S sequencing indicated little genotype differences in mucosal associated bacterial communities in relative abundance, beta diversity, or alpha diversity (Figure S8). These data suggest the mucosal associated fungal population differs from luminal digesta and PYY may influence membership in a manner consistent with prevention of Candida colonization.

\section{Clinical relevance of PC-PYY to patients with Crohn's Disease involving the terminal ileum}


Several lines of investigation have supported the notion that the subset of patients with Crohn's disease involving the terminal ileum (iCD) may have defects in Paneth Cell function (Adolph et al., 2013; Wehkamp et al., 2005). Major gene variants associated with increased risk for Inflammatory Bowel Disease (IBD) in a patients of European ancestry, for instance, have been linked to autophagic defects in these cells, and histopathological features of ileal Paneth Cells associated with iCD have been described (Cadwell et al., 2009; Stappenbeck et al., 2011; Wang et al., 2018). To explore this possibility, we performed a limited survey of iCD patients and normal controls who were sampled endoscopically. As most of the iCD patients had stricturing or severe edema of the terminal ileum that did not allow passage of the endoscope and sampling at sites of active inflammation, samples were primarily collected from sites downstream of active disease.

We found increased total fungal and $C$. albicans $\mathrm{CFU}$ counts in the terminal ileal mucosa of $11 \mathrm{iCD}$ patients compared to 5 non-IBD controls subjects (Figure 7A). While this is a small sampling, it confirms findings from several other previously published findings, (Li et al., 2014; Hoarau, et al., 2016; Sokol et al., 2017a). Intestinal 2-dimensional (2D) epithelial organoid monolayers (In et al., 2016) were derived from stem cells of human distal ileal pinch biopsies obtained by colonoscopy in $3 \mathrm{iCD}$ and 3 non-IBD control subjects. As shown in Figures 8B and $8 \mathrm{C}$, these monolayers were next exposed to $C$. albicans yeast to examine whether they would adhere to the monolayers and to what extent they might transform to the more virulent hyphal forms. The quantitation of relative hyphal form abundance to total yeast in each field of view at $20 \mathrm{hrs}$ is presented (Figure 7B). Filamentous C. albicans hyphae are clearly evident in monolayers from iCD patients in contrast to healthy cell monolayers (Figure 7C). While there are limitations to the interpretation of these in vitro data where cells have been passed over numerous generations in the presences of growth factors and then differentiation buffer, these findings suggest that iCD cells may be inherently permissive for fungal virulence. Our findings that PC-PYY may be important for maintenance of fungal commensalism provides a potential mechanism for this difference in permissiveness between organoids derived from healthy and control patients. Further investigations will be required to validate and extend these observations in larger human based studies. Finally, we propose a working model for PYY regulation of fungal pathogens in iCD (Graphical Abstract).

\section{DISCUSSION}

Little is known about the host-mycobiome interactions in the gut. Fungi are present in the "healthy" gut microbiome, particularly the yeast Candida albicans, which is found in at least $70 \%$ of healthy humans (Odds, 1988). In addition to its well-known role as an opportunistic pathogen, recent studies indicate $C$. albicans may exert positive effects on immune development in healthy hosts (Jian et al., 2017; Shao et al., 2019; Bacher et al., 2019). Moreover, recent genetic analysis of $\mathrm{C}$. albicans in a murine colonization model suggests that the host actively curate the fungal population by restricting $C$. albicans growth in response to excess antigenic 
markers of invasive hyphae (Witchley et al., 2019). In this setting, our discovery of unanticipated antimicrobial activity of the well-known satiety hormone, PYY, seems particularly relevant. Peptide YY (PYY) is a 36 amino acid-residue peptide that is highly conserved in vertebrate species, where its structure is virtually unchanged between cartilaginous fish and humans (Conlon, 2002). Since its discovery in porcine intestine and brain stem tissue in 1982 (Glavas et al., 2008; Tatemoto, 1982), diverse regulatory roles have been identified for PYY, mostly involving metabolic regulation (Batterham et al., 2007; Hill et al., 2011; Holzer et al., 2012). In the mammalian and human intestine, PYY is notably released into the bloodstream by ' $\mathrm{L}$ cells', a subset of enteroendocrine cells (EECs) that are most numerous in the distal ileum and colon

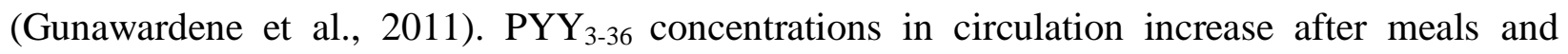
decrease with fasting, supporting its function as a satiety peptide for regulating hunger and mediating gut physiology (Murphy and Bloom, 2006). Here, we report that PYY is also expressed in distinct, non-lysosomal secretory granules of murine and human Paneth cells. Unlike L cells, Paneth cells play important roles in innate immunity by producing antimicrobial peptides that regulate microbial assemblage and deter pathogens. The presence of PYY in PC secretory granules therefore raised the possibility that PYY has a previously unrecognized biological function, that of an antimicrobial peptide. PYY also has structural features and charge characteristics that are strikingly similar to the amphibian antimicrobial peptide, magainin-2. We therefore set out to determine if PYY had antibacterial activity. Surprisingly, PYY has modest effects and failed to inhibit the proliferation or viability of a variety of bacteria even at high doses. Nevertheless, based on published observations that magainin-2 on the skin of aquatic frogs has anti-fungal properties, we examined the in vitro activity of PYY against fungi. As described above, Candida albicans is the primary fungus associated with the human gut. $C$. albicans can adopt multiple cell morphologies, with round-to-oval, single celled yeasts behaving as commensals and highly elongated, multicellular hyphae and pseudohyphae associated with virulence in the GI milieu (Sudbery et al., 2004; Staib and Morschhäuser, 2007; Sudbery, 2011; Thompson et al., 2011). Interestingly, the addition of either PYY has specific activity against the hyphal (virulent), but not yeast (commensal), forms of $C$. albicans under hyphae-inducing conditions. PYY also inhibits cell respiration in hyphae, but not yeast, and inhibits biofilm formation. The mechanism of fungal cell injury by PYY appears to involve direct membrane disruption mediated by charge interactions at the surface, similar to other AMPs, as uptake of propidium iodide occurs where FITC-labeled PYY binds the hyphal membranes and causes membrane blebbing and irregularities. Moreover, the anionic surface charge of C. albicans hyphae, in contrast to the absence of this in the yeast form (Figure 4A) attracts PC-PYY binding through electrostatic interactions. From these data, we conclude that: (1) PC-PYY differs from the endocrine-PYY in structure, function, action, (2) PC-PYY is a novel and functionally specific AMP that specifically targets the virulent form of $C$. albicans to maintain a healthy state of fungal commensalism in the gut, (3) PC-PYY is packaged in secretory granules that are distinct from those that carry lysozyme and is released by mucosal exposure to intact hyphae, and not yeast $C$. albicans, (4) the specificity of the cationic PC-PYY for the former lies in its initial 
electrostatic interaction with the anionic surface charge of $C$. albicans hyphae, which the yeast form does not have, (5) once secreted PC-PYY is retained by overlying mucus for which it has proclivity and which in turn provides optimal conditions for its activity and protection from DPP-IV cleavage, and (6) Mucus fortified with PC-PYY kills and prevents further penetration by virulent $C$. albicans. At the same time, PC-PYY has limited effects on commensal $C$. albicans yeast and other members of the gut microbiome. This microbial selectivity, activation, and mucus compartmentalization of PC-PYY distinguishes it from other innate immune AMPs which have broad ranges of action (Bevins and Salzman, 2011; Mukherjee and Hooper, 2015), representing an elegant mechanism by which the host can prevent the development of pathogenesis while retaining its commensal fungal mycobiome.

The dual functions of peptide $\mathrm{YY}$ as an innate antimicrobial peptide and an anti-satiety hormonal peptide bears special mention. PYY joins a growing list of mammalian proteins and peptides that have been demonstrated to serve multiple discrete functions within the host (Broderick, 2015). In the case of PYY, this involves a proteolytic (DPP-IV) cleavage of the two N-terminal amino acids, transforming the AMP form, $\mathrm{PYY}_{1-36}$, that utilizes biophysic (electrostatic and lipid disruption) action to kill $C$. albicans hyphae to the hormone form, $\mathrm{PYY}_{3-}$ 36, that binds and signals through a Y2-membrane receptor (Batterham et al., 2002, 2007; Holzer et al., 2012). In this regard, there is little cross-over in function by these two PYY entities. The major circulating form, $\mathrm{PYY}_{3-36}$, has limited anti-fungal activity, whereas, $\mathrm{PYY}_{1-36}$, has far less binding affinity for the Y2 receptor and hormonal activity (Batterham et al., 2006). The repurposing of the PYY molecule appears dependent on non-genomic factors that include the nature of extracellular stimulus, systemic vs luminal-directed secretion, the milieu (mucus vs plasma), and mucus conferred protection of the PYY ${ }_{1-36}$ from enzymatic cleavage by DPP-IV which would convert it to an endocrine form.

Finally, we believe our findings may have relevance to human health and disease. In health, expression of PC-PYY in humans has been corroborated which likely serves as a unique antimicrobial peptide that plays a role in maintaining a commensal state in a critical transitional zone between vastly different small and large bowel microbiota. Weakening or dysfunction of Paneth cells in the terminal ileum (and appendix) can perturb the often delicate balance between host and microbe, resulting in increased risk or frank development of disease, particularly in genetically susceptible hosts. In IBD, particularly Crohn's disease involving the terminal ileum, Paneth cell dysfunction and fungi have been implicated in disease pathogenesis, but the supporting evidence is minimal and often circumstantial. Several studies have reported increased titers of $C$. albicans in stool samples of ileal CD patients (Sokol et al., 2017a). Serum anti-fungal antibodies, particularly ASCA (anti-Saccharomyces cerevisiae antibody), also appear to be predictive of risk and severity of CD (Israeli et al., 2005; Ksiadzyna et al., 2009). In fact, ASCA is the single most robust biomarker manifestation of CD (Barnes et al., 1990; McKenzie et al., 1990; Giaffer et al., 1992; Quinton et al., 1998),particularly involving gastroduodenal and small bowel rather than colonic disease and associated with the likelihood of having more severe disease requiring surgery within a 9-year follow-up period (Walker et al., 2004). ASCA is 
directed against mannan, a polysaccharide that decorates the cell walls of many fungi, including C. albicans. The induction of IgG against this cell wall component is thought to reflect fungal invasion of the gut epithelium, a property not associated with normal commensalism. In addition, mice lacking Dectin-1, an innate immune pattern-recognition receptor for another fungal cell wall component, $\beta$-1,3-glucan, have increased susceptibility to chemically induced colitis, attributed to increased epithelial invasion by Candida species. Human polymorphisms of Dectin1 (CLEC7A) and CARD9, both part of an innate immune signaling pathway, are strongly linked to a severe form of ulcerative colitis, autoimmune disorders, and Candidiasis (Khor et al., 2011; Jia et al., 2014; Underhill and Iliev, 2014; Lanternier et al., 2015). Despite these intriguing hints of a role for fungi in IBD, the behavior of fungi within the gut has been largely uncharacterized.

Crohn's disease of the terminal ileum (iCD) has also been associated with Paneth cell dysfunction/injury and histopathology (Liu et al., 2016). In some, but not all, these defects have been linked to IBD gene risk variants associated with aberrations in autophagic functions (e.g. NOD2, ATG16L1 T300A, IRGM, and LRRK2 (Anderson et al., 2011; Fritz et al., 2011; Khor et al., 2011; Van Limbergen et al., 2014; Lanternier et al., 2015). Defective Paneth cell function can lead to the development of intestinal dysbiosis (Wang et al., 2018; Wehkamp et al., 2005). Both Paneth cell dysfunction and mucus-depletion (which is common in chronic inflammation of the gut) could result in decreased PC-PYY activity, permitting common fungal commensals like $C$. albicans to transform into virulent hyphae that can attach, form biofilm, invade the mucosal barrier and mucosa, and trigger or contribute to the development of iCD. We attempted to explore this possibility using both in vitro and in vivo approaches and demonstrated (1) PYY $\mathrm{PY}_{1-36}$ inhibits $C$. albicans hyphae from attaching to Caco2 colonic epithelial monolayers, (2) increased clearance of $C$. albicans in a murine model with oral PYY administration, (3) increased $C$. albicans colonization in $\mathrm{PYY}^{-/}$-gene deficient mice, (4) increased $C$. albicans load from ileal samples acquired endoscopically from patients with active $\mathrm{iCD}$, and (5) increased attachment of C. albicans hyphae to 2D-organoid monolayers from iCD patients compared to non-IBD controls 2D monolayers. Unfortunately, direct measurements of mucus and mucosal PYY levels were technically not possible because the narrow passage caused by edema and fibrosis did not permit intubation of the endoscope into active areas. Collectively, these data suggest that iCD patients have an increased $C$. albicans load and that PYY, both in vitro and in vivo, can deter C. albicans attachment to the mucosa.

In summary, we propose that PC-PYY is a unique antimicrobial peptide that differs from its endocrine counterpart in structure, biological action, and function. While it is found in virtually all vertebrate lineages, these observations raise questions about the origins of endocrine molecules and about nature's repurposing of conserved molecules for multiple homeostatic purposes in the host. Regulation and selective actions of PYY to the virulent form of C. albicans further distinguishes it amongst other innate immune peptides, implicating a role in regulating key elements of the gut mycobiome. In active iCD, it may very well be that PC-PYY bioavailability, stability, and bioactivity are compromised by Paneth cell dysfunction and mucus 
cell depletion, providing fungi like Candida albicans with the opportunity to become virulent, adherent, and invasive, and to contribute to the etiopathogenesis of the disease.

\section{ACKNOWLEDGMENTS}

We acknowledge the MRSEC Shared User Facilities at the University of Chicago (NSF DMR1420709) and the Mass Spectrometry Facility (NSF CHE-1048528). The authors thank Daina L. Ringus, Hyoann Choi, Mirae Lee and Monika Krezalek for helpful discussions. We would like to acknowledge Vytas Bindokas at the Integrated Light Microscopy Core. We thank the Garvan Institute of Medical Research and Dr. Herzog for generously providing the PYY knockout line (Batterham et al., 2006)

\section{AUTHOR CONTRIBUTIONS}

JFP and EBC were involved in every aspect of this study, including the discovery, conception, experimentation, data analysis, and MS preparation; SMN, JW, VL, HH, DLT, AS, KGH, AK, $\mathrm{XZ}, \mathrm{YT}, \mathrm{CMC}, \mathrm{OZ}, \mathrm{JA}$, and LW each had a key role in contributing to the conceptual, experimental, and data analysis components of this study.

\section{DECLARATION OF INTERESTS}

EBC, JFP, and KGH are co-founders and shareholders of AVnovum Therapeutic, Inc which is developing novel antimicrobial peptides for fungal infections.

\section{REFERENCES}

Adolph, T. E., Tomczak, M. F., Niederreiter, L., Ko, H. J., Böck, J., Martinez-Naves, E., Glickman, J. N., Tschurtschenthaler, M., Hartwig, J., Hosomi, S., Flak, M. B., Cusick, J. L., Kohno, K., Iwawaki, T., Billmann-Born, S., Raine, T., Bharti, R., Lucius, R., Kweon, M. N., ... Blumberg, R. S. (2013). Paneth cells as a site of origin for intestinal inflammation. Nature, 503(7475), 272-276. https://doi.org/10.1038/nature12599

Anderson, C. A., Boucher, G., Lees, C. W., Franke, A., D’Amato, M., Taylor, K. D., Lee, J. C., Goyette, P., Imielinski, M., Latiano, A., Lagacé, C., Scott, R., Amininejad, L., Bumpstead, S., Baidoo, L., Baldassano, R. N., Barclay, M., Bayless, T. M., Brand, S., ... Rioux, J. D. (2011). Meta-analysis identifies 29 additional ulcerative colitis risk loci, increasing the number of confirmed associations to 47. In Nature Genetics (Vol. 43, Issue 3, pp. 246-252). Nature Publishing Group. https://doi.org/10.1038/ng.764

Barnes, R. M. R., Allan, S., Taylor-Robinson, C. H., Finn, R., \& Johnson, P. M. (1990). Serum antibodies reactive with Saccharomyces cerevisiae in inflammatory bowel disease: Is IgA antibody a marker for crohn's disease? International Archives of Allergy and Immunology, 92(1), 9-15. https://doi.org/10.1159/000235217

Batterham, R. L., Cowley, M. A., Small, C. J., Herzog, H., Cohen, M. A., Dakin, C. L., Wren, A. M., 
Brynes, A. E., Low, M. J., Ghatei, M. A., Cone, R. D., \& Bloom, S. R. (2002). Gut hormone PYY336 physiologically inhibits food intake. Nature, 418(6898), 650-654.

https://doi.org/10.1038/nature00887

Batterham, R. L., Ffytche, D. H., Rosenthal, J. M., Zelaya, F. O., Barker, G. J., Withers, D. J., \& Williams, S. C. R. (2007). PYY modulation of cortical and hypothalamic brain areas predicts feeding behaviour in humans. Nature, 450(7166), 106-109. https://doi.org/10.1038/nature06212

Batterham, R. L., Heffron, H., Kapoor, S., Chivers, J. E., Chandarana, K., Herzog, H., Le Roux, C. W., Thomas, E. L., Bell, J. D., \& Withers, D. J. (2006). Critical role for peptide YY in protein-mediated satiation and body-weight regulation. Cell Metabolism, 4(3), 223-233. https://doi.org/10.1016/j.cmet.2006.08.001

Bevins, C. L., \& Salzman, N. H. (2011). Paneth cells, antimicrobial peptides and maintenance of intestinal homeostasis. Nature Reviews Microbiology, 9(5), 356-368. https://doi.org/10.1038/nrmicro2546

Broderick, N. A. (2015). A common origin for immunity and digestion. Frontiers in Immunology, 6(FEB), 72. https://doi.org/10.3389/fimmu.2015.00072

Cadwell, K., Patel, K. K., Komatsu, M., Virgin IV, H. W., \& Stappenbeck, T. S. (2009). A common role for Atg16L1, Atg5 and Atg7 in small intestinal Paneth cells and Crohn disease. Autophagy, 5(2), 250-252. https://doi.org/10.4161/auto.5.2.7560

Clevers, H. C., \& Bevins, C. L. (2013). Paneth cells: maestros of the small intestinal crypts. Annual Review of Physiology, 75, 289-311. https://doi.org/10.1146/annurev-physiol-030212-183744

Conlon, J. M. (2002). The origin and evolution of peptide YY (PYY) and pancreatic polypeptide (PP). Peptides, 23(2), 269-278. https://doi.org/10.1016/S0196-9781(01)00608-8

Costello, E. K., Lauber, C. L., Hamady, M., Fierer, N., Gordon, J. I., \& Knight, R. (2009). Bacterial community variation in human body habitats across space and time. Science, 326(5960), 1694 1697. https://doi.org/10.1126/science.1177486

Darmoul, D., Voisin, T., Couvineau, A., Rouyer-Fessard, C., Salomon, R., Wang, Y., Swallow, D. M., \& Laburthe, M. (1994). Regional expression of epithelial dipeptidyl peptidase IV in the human intestines. Biochemical and Biophysical Research Communications, 203(2), 1224-1229. https://doi.org/10.1006/bbrc.1994.2313

Fritz, T., Niederreiter, L., Adolph, T., Blumberg, R. S., \& Kaser, A. (2011). Crohn's disease: NOD2, autophagy and ER stress converge. In Gut (Vol. 60, Issue 11, pp. 1580-1588). BMJ Publishing Group. https://doi.org/10.1136/gut.2009.206466

Giaffer, M. H., Clark, A., \& Holdsworth, C. D. (1992). Antibodies to Saccharomyces cerevisiae in patients with Crohn's disease and their possible pathogenic importance. Gut, 33(8), 1071-1075. https://doi.org/10.1136/gut.33.8.1071

Glavas, M. M., Grayson, B. E., Allen, S. E., Copp, D. R., Smith, M. S., Cowley, M. A., \& Grove, K. L. (2008). Characterization of brainstem peptide YY (PYY) neurons. The Journal of Comparative Neurology, 506(2), 194-210. https://doi.org/10.1002/cne.21543

Grandt, D., Schimiczek, M., Beglinger, C., Layer, P., Goebell, H., Eysselein, V. E., \& Reeve, J. R. (1994). Two molecular forms of Peptide YY (PYY) are abundant in human blood: characterization of a radioimmunoassay recognizing PYY 1-36 and PYY 3-36. Regulatory Peptides, 51(2), 151-159. https://doi.org/10.1016/0167-0115(94)90204-6

Greeley, G. J., Hill, F. L., Spannagel, A., \& Thompson, J. C. (1987). Distribution of peptide YY in the gastrointestinal tract of the rat, dog, and monkey. Regul Pept, 19(5-6), 365-372.

Gunawardene, A. R., Corfe, B. M., \& Staton, C. A. (2011). Classification and functions of enteroendocrine cells of the lower gastrointestinal tract. International Journal of Experimental Pathology, 92(4), 219-231. https://doi.org/10.1111/j.1365-2613.2011.00767.x

Haber, A. L., Biton, M., Rogel, N., Herbst, R. H., Shekhar, K., Smillie, C., Burgin, G., Delorey, T. M., Howitt, M. R., Katz, Y., Tirosh, I., Beyaz, S., Dionne, D., Zhang, M., Raychowdhury, R., Garrett, W. S., Rozenblatt-Rosen, O., Shi, H. N., Yilmaz, O., ... Regev, A. (2017). A single-cell survey of the small intestinal epithelium. Nature, 551(7680), 333-339. https://doi.org/10.1038/nature24489 
Hill, B. R., de Souza, M. J., \& Williams, N. I. (2011). Characterization of the diurnal rhythm of peptide YY and its association with energy balance parameters in normal-weight premenopausal women. American Journal of Physiology - Endocrinology and Metabolism, 301(2). https://doi.org/10.1152/ajpendo.00171.2011

Hoarau, G., Mukherjee, P. K., Gower-rousseau, C., Hager, C., Chandra, J., Retuerto, M. A., Neut, C., Vermeire, S., Clemente, J., Colombel, J. F., Fujioka, H., Poulain, D., Sendid, B., \& Ghannoum, M. A. (2016). Bacteriome and Mycobiome Interactions Underscore Microbial Dysbiosis in Familial Crohn's Disease. MBio, 7(5), e01250-16. https://doi.org/10.1128/mBio.01250-16

Holzer, P. (2016). Neuropeptides, Microbiota, and Behavior. In International Review of Neurobiology (1st ed., Vol. 131, Issue 6, pp. 67-89). Elsevier Inc. https://doi.org/10.1016/bs.irn.2016.08.005

Holzer, P., Reichmann, F., \& Farzi, A. (2012). Neuropeptide Y, peptide YY and pancreatic polypeptide in the gut-brain axis. In Neuropeptides (Vol. 46, Issue 6, pp. 261-274). Churchill Livingstone. https://doi.org/10.1016/j.npep.2012.08.005

Iliev, I. D., Funari, V. A., Taylor, K. D., Nguyen, Q., Reyes, C. N., Strom, S. P., Brown, J., Becker, C. A., Fleshner, P. R., Dubinsky, M., Rotter, J. I., Wang, H. L., McGovern, D. P. B., Brown, G. D., \& Underhill, D. M. (2012). Interactions Between Commensal Fungi and the C-Type Lectin Receptor Dectin-1 Influence Colitis. Science, 336(6086), 1314-1317. https://doi.org/10.1126/science.1221789

In, J., Foulke-Abel, J., Zachos, N. C., Hansen, A. M., Kaper, J. B., Bernstein, H. D., Halushka, M., Blutt, S., Estes, M. K., Donowitz, M., \& Kovbasnjuk, O. (2016). Enterohemorrhagic Escherichia coli Reduces Mucus and Intermicrovillar Bridges in Human Stem Cell-Derived Colonoids. CMGH, 2(1), 48-62.e3. https://doi.org/10.1016/j.jcmgh.2015.10.001

Israeli, E., Grotto, I., Gilburd, B., Balicer, R. D., Goldin, E., Wiik, A., \& Shoenfeld, Y. (2005). AntiSaccharomyces cerevisiae and antineutrophil cytoplasmic antibodies as predictors of inflammatory bowel disease. Gut, 54(9), 1232-1236. https://doi.org/10.1136/gut.2004.060228

Jia, X. M., Tang, B., Zhu, L. Le, Liu, Y. H., Zhao, X. Q., Gorjestani, S., Hsu, Y. M. S., Yang, L., Guan, J. H., Xu, G. T., \& Lin, X. (2014). CARD9 mediates Dectin-1-induced ERK activation by linking RasGRF1 to H-Ras for antifungal immunity. Journal of Experimental Medicine, 211(11), 2307-2321. https://doi.org/10.1084/jem.20132349

Kagan, B. L., Ganz, T., \& Lehrer, R. I. (1994). Defensins: a family of antimicrobial and cytotoxic peptides. Toxicology, 87(1-3), 131-149. https://doi.org/10.1016/0300-483X(94)90158-9

Keire, D. A., Kobayashi, M., Solomon, T. E., \& Reeve, J. R. (2000). Solution structure of monomeric peptide YY supports the functional significance of the PP-fold. Biochemistry, 39(32), 9935-9942. https://doi.org/10.1021/bi992576a

Keire, David A., Whitelegge, J. P., Souda, P., Faull, K. F., Bassilian, S., Reidelberger, R. D., Haver, A. C., \& Reeve, J. R. (2010). PYY(1-36) is the major form of PYY in rat distal small intestine: Quantification using high-resolution mass spectrometry. Regulatory Peptides, 165(2-3), 151-157. https://doi.org/10.1016/j.regpep.2010.06.006

Khor, B., Gardet, A., \& Xavier, R. J. (2011). Genetics and pathogenesis of inflammatory bowel disease. Nature, 474(7351), 307-317. https://doi.org/10.1038/nature10209

Ksiadzyna, D., Semianow-Wejchert, J., Nawrot, U., Wlodarczyk, K., \& Paradowski, L. (2009). Serum concentration of interleukin 10, anti-mannan Candida antibodies and the fungal colonization of the gastrointestinal tract in patients with ulcerative colitis. Advances in Medical Sciences, 54(2), 170176. https://doi.org/10.2478/v10039-009-0023-6

Lanternier, F., Mahdaviani, S. A., Barbati, E., Chaussade, H., Koumar, Y., Levy, R., Denis, B., Brunel, A. S., Martin, S., Loop, M., Peeters, J., De Selys, A., Vanclaire, J., Vermylen, C., Nassogne, M. C., Chatzis, O., Liu, L., Migaud, M., Pedergnana, V., ... Puel, A. (2015). Inherited CARD9 deficiency in otherwise healthy children and adults with Candida species-induced meningoencephalitis, colitis, or both. Journal of Allergy and Clinical Immunology, 135(6), 1558-1568.e2. https://doi.org/10.1016/j.jaci.2014.12.1930

Lee, S. M., Donaldson, G. P., Mikulski, Z., Boyajian, S., Ley, K., \& Mazmanian, S. K. (2013). Bacterial colonization factors control specificity and stability of the gut microbiota. Nature, 501(7467), 426- 
429. https://doi.org/10.1038/nature12447

Li, Q., Wang, C., Tang, C., \& He, Q. (2014). Dysbiosis of Gut Fungal Microbiota is Associated With Mucosal Inflammation in Crohn's ' Disease. Journal of Clinical Gastroenterology, 48(6), 513-523. https://doi.org/10.1097/MCG.0000000000000035

Liu, T.-C., Gurram, B., Baldridge, M. T., Head, R., Lam, V., Luo, C., Cao, Y., Simpson, P., Hayward, M., Holtz, M. L., Bousounis, P., Noe, J., Lerner, D., Cabrera, J., Biank, V., Stephens, M., Huttenhower, C., McGovern, D. P. B., Xavier, R. J., ... Salzman, N. H. (2016). Paneth cell defects in Crohn's disease patients promote dysbiosis. JCI Insight, 1(8), e86907. https://doi.org/10.1172/jci.insight.86907

Mahlapuu, M., Håkansson, J., Ringstad, L., \& Björn, C. (2016). Antimicrobial peptides: An emerging category of therapeutic agents. In Frontiers in Cellular and Infection Microbiology (Vol. 6, Issue DEC, p. 194). Frontiers Media S.A. https://doi.org/10.3389/fcimb.2016.00194

McKenzie, H., Main, J., Pennington, C. R., \& Parratt, D. (1990). Antibody to selected strains of Sacharomyces cerevisiae (baker's and brewer's yeast) and Candida albicans in Crohn's disease. Gut, 31(5), 536-538. https://doi.org/10.1136/gut.31.5.536

Michel, M. C., Fliers, E., \& Van Noorden, C. J. F. (2008). Dipeptidyl peptidase IV inhibitors in diabetes: More than inhibition of glucagon-like peptide-1 metabolism? In Naunyn-Schmiedeberg's Archives of Pharmacology (Vol. 377, Issue 3, pp. 205-207). Springer. https://doi.org/10.1007/s00210-0080280-0

Moyes, D. L., Runglall, M., Murciano, C., Shen, C., Nayar, D., Thavaraj, S., Kohli, A., Islam, A., MoraMontes, H., Challacombe, S. J., \& Naglik, J. R. (2010). A biphasic innate immune MAPK response discriminates between the yeast and hyphal forms of candida albicans in epithelial cells. Cell Host and Microbe, 8(3), 225-235. https://doi.org/10.1016/j.chom.2010.08.002

Mukaremera, L., Lee, K. K., Mora-Montes, H. M., \& Gow, N. A. R. (2017). Candida albicans yeast, pseudohyphal, and hyphal morphogenesis differentially affects immune recognition. Frontiers in Immunology, 8(JUN). https://doi.org/10.3389/fimmu.2017.00629

Mukherjee, S., \& Hooper, L. V. (2015). Antimicrobial defense of the intestine. Immunity, 42(1), 28-39. https://doi.org/10.1016/j.immuni.2014.12.028

Murphy, K. G., \& Bloom, S. R. (2006). Gut hormones and the regulation of energy homeostasis. In Nature (Vol. 444, Issue 7121, pp. 854-859). Nature Publishing Group. https://doi.org/10.1038/nature05484

Noble, S. M., Gianetti, B. A., \& Witchley, J. N. (2017). Candida albicans cell-type switching and functional plasticity in the mammalian host. In Nature Reviews Microbiology (Vol. 15, Issue 2, pp. 96-108). Nature Publishing Group. https://doi.org/10.1038/nrmicro.2016.157

Odds, F. C. (1988). Candida and Candidosis. A review and bibliography. In Baillière Tindall.

Phadke, S. M., Lazarevic, V., Bahr, C. C., Islam, K., Stolz, D. B., Watkins, S., Tencza, S. B., Vogel, H. J., Montelaro, R. C., \& Mietzner, T. A. (2002). Lentivirus lytic peptide 1 perturbs both outer and inner membranes of Serratia marcescens. Antimicrobial Agents and Chemotherapy, 46(6), 2041-2045. https://doi.org/10.1128/AAC.46.6.2041-2045.2002

Quinton, J. F., Sendid, B., Reumaux, D., Duthilleul, P., Cortot, A., Grandbastien, B., Charrier, G., Targan, S. R., Colombel, J. F., \& Poulain, D. (1998). Anti-Saccharomyces cerevisiae mannan antibodies combined with antineutrophil cytoplasmic autoantibodies in inflammatory bowel disease: prevalence and diagnostic role. Gut, 42(6), 788-791. http://www.ncbi.nlm.nih.gov/pubmed/9691915

Rakoff-Nahoum, S., Pglino, J., Eslami-Varzaneh, F., Edberg, S., \& Medzhitov, R. (2004). Recognition of comensal microflora by toll-like receptors in required for intestinal homeostasis. Cell, 118, 229-241.

Sokol, H., Leducq, V., Aschard, H., Pham, H. P., Jegou, S., Landman, C., Cohen, D., Liguori, G., Bourrier, A., Nion-Larmurier, I., Cosnes, J., Seksik, P., Langella, P., Skurnik, D., Richard, M. L., \& Beaugerie, L. (2017a). Fungal microbiota dysbiosis in IBD. Gut, 66(6), 1039-1048. https://doi.org/10.1136/gutjnl-2015-310746

Sokol, H., Leducq, V., Aschard, H., Pham, H. P., Jegou, S., Landman, C., Cohen, D., Liguori, G., Bourrier, A., Nion-Larmurier, I., Cosnes, J., Seksik, P., Langella, P., Skurnik, D., Richard, M. L., \& 
Beaugerie, L. (2017b). Supplementary Materials and Methods:Fungal microbiota dysbiosis in IBD. Gut, 66(6), 1-7. https://doi.org/10.1136/gutjnl-2015-310746

Staib, P., \& Morschhäuser, J. (2007). Chlamydospore formation in Candida albicans and Candida dubliniensis - An enigmatic developmental programme. In Mycoses (Vol. 50, Issue 1, pp. 1-12). https://doi.org/10.1111/j.1439-0507.2006.01308.x

Stappenbeck, T. S., Rioux, J. D., Mizoguchi, A., Saitoh, T., Huett, A., Darfeuille-Michaud, A., Wileman, T., Mizushima, N., Carding, S., Akira, S., Parkes, M., \& Xavier, R. J. (2011). Crohn disease: A current perspective on genetics, autophagy and immunity. In Autophagy (Vol. 7, Issue 4, pp. 355374). Taylor and Francis Inc. https://doi.org/10.4161/auto.7.4.13074

Sudbery, P. E. (2011). Growth of Candida albicans hyphae. Nature Reviews Microbiology, 9(10), $737-$ 748. https://doi.org/10.1038/nrmicro2636

Sudbery, P., Gow, N., \& Berman, J. (2004). The distinct morphogenic states of Candida albicans. Trends in Microbiology, 12(7), 317-324. https://doi.org/10.1016/j.tim.2004.05.008

Tatemoto, K. (1982). Isolation and characterization of peptide YY (PYY), a candidate gut hormone that inhibits pancreatic exocrine secretion. Proceedings of the National Academy of Sciences of the United States of America, 79(8 I), 2514-2518. https://doi.org/10.1073/pnas.79.8.2514

Thompson, D. S., Carlisle, P. L., \& Kadosh, D. (2011). Coevolution of Morphology and Virulence in Candida Species. Eukaryotic Cell, 10(9), 1173-1182. https://doi.org/10.1128/EC.05085-11

Underhill, D. M., \& Iliev, I. D. (2014). The mycobiota: interactions between commensal fungi and the host immune system. Nature Reviews Immunology, 14(6), 405-416. https://doi.org/10.1038/nri3684

van der Weerden, N. L., Bleackley, M. R., \& Anderson, M. A. (2013). Properties and mechanisms of action of naturally occurring antifungal peptides. Cellular and Molecular Life Sciences, 70(19), 3545-3570. https://doi.org/10.1007/s00018-013-1260-1

Van Limbergen, J., Radford-Smith, G., \& Satsangi, J. (2014). Advances in IBD genetics. In Nature Reviews Gastroenterology and Hepatology (Vol. 11, Issue 6, pp. 372-385). Nature Publishing Group. https://doi.org/10.1038/nrgastro.2014.27

Walker, L. J., Aldhous, M. C., Drummond, H. E., Smith, B. R. K., Nimmo, E. R., Arnott, I. D. R., \& Satsangi, J. (2004). Anti-Saccharomyces cerevisiae antibodies (ASCA) in Crohn's disease are associated with disease severity but not NOD2/CARD15 mutations. Clinical and Experimental Immunology, 135(3), 490-496. https://doi.org/10.1111/j.1365-2249.2003.02392.x

Wang, S. L., Shao, B. Z., Zhao, S. B., Fang, J., Gu, L., Miao, C. Y., Li, Z. S., \& Bai, Y. (2018). Impact of paneth cell autophagy on inflammatory bowel disease. In Frontiers in Immunology (Vol. 9, Issue APR). Frontiers Media S.A. https://doi.org/10.3389/fimmu.2018.00693

Weerasekera, M. M., Wijesinghe, G. K., Jayarathna, T. A., Gunasekara, C. P., Fernando, N., Kottegoda, N., \& Samaranayake, L. P. (2016). Culture media profoundly affect Candida Albicans and Candida tropicalis growth, adhesion and biofilm development. Memorias Do Instituto Oswaldo Cruz, 111(11), 697-702. https://doi.org/10.1590/0074-02760160294

Wehkamp, J., Salzman, N. H., Porter, E., Nuding, S., Weichenthal, M., Petras, R. E., Shen, B., Schaeffeler, E., Schwab, M., Linzmeier, R., Feathers, R. W., Chu, H., Lima, H., Fellermann, K., Ganz, T., Stange, E. F., \& Bevins, C. L. (2005). Reduced Paneth cell -defensins in ileal Crohn's disease. Proceedings of the National Academy of Sciences, 102(50), 18129-18134. https://doi.org/10.1073/pnas.0505256102

Witchley, J. N., Penumetcha, P., Abon, N.V., Woolford, C. A., Mitchell, A. P., Noble, S. M. Candida albicans Morphogenesis Programs Control the Balance between Gut Commensalism and Invasive Infection. Cell Host Microbe, 25(3):432-443. https://doi.org/10.1016/j.chom.2019.02.008 


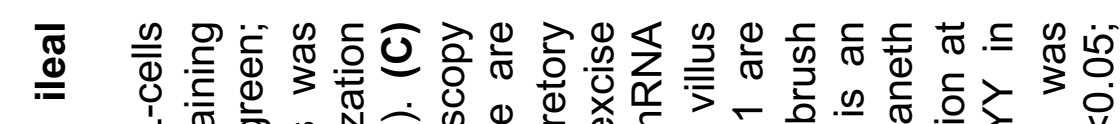

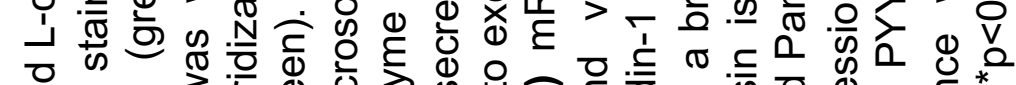

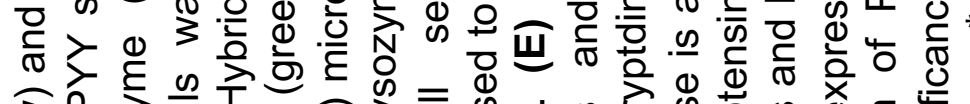

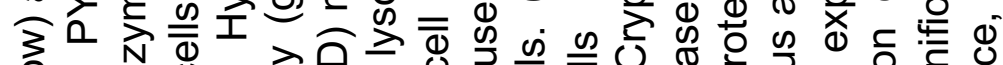

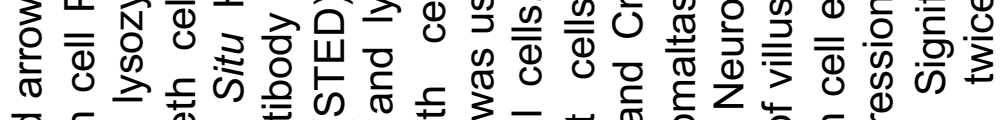

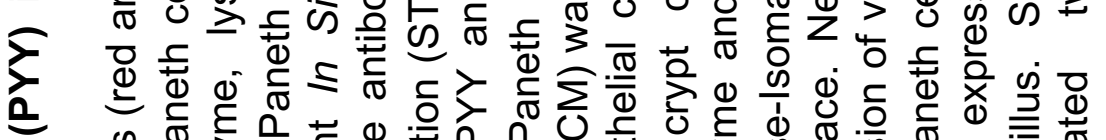

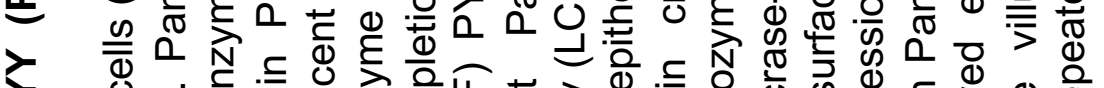

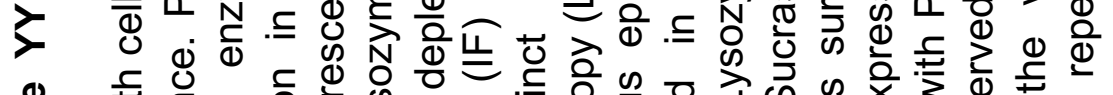

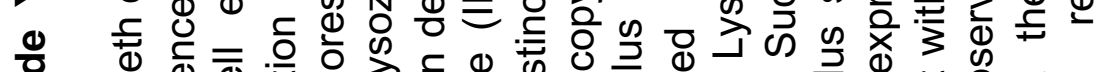

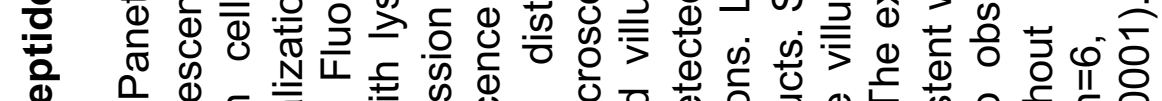
Q ᄂ ○ ब

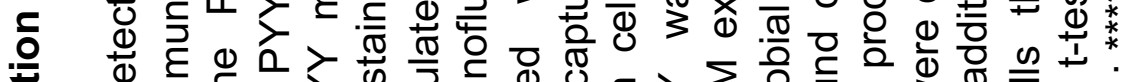

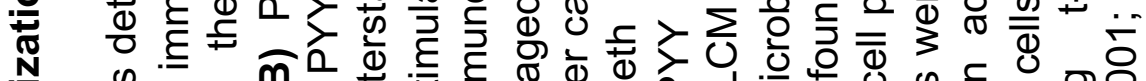

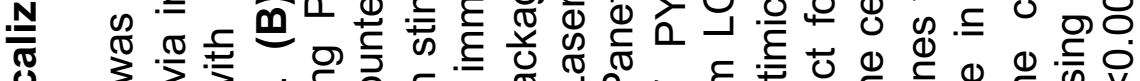

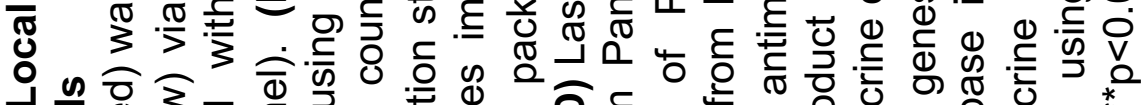

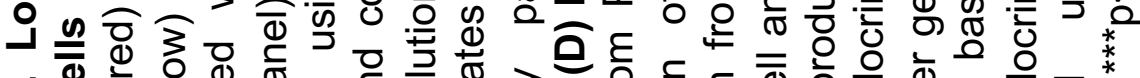
- Uัخ ఏ 둰

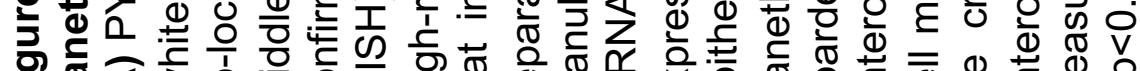

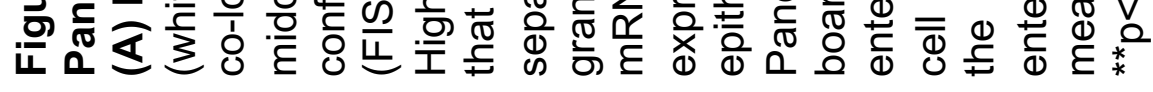
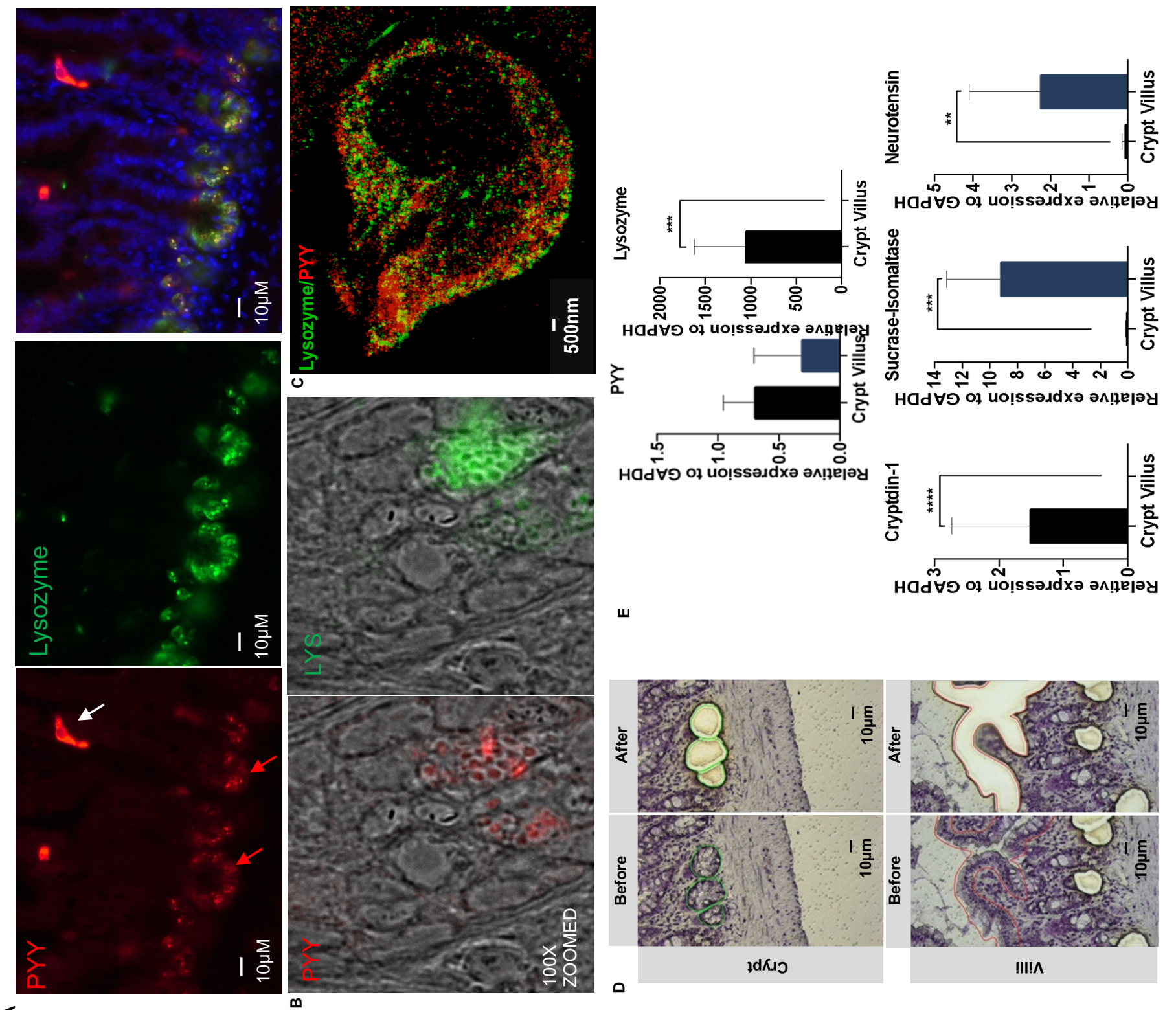


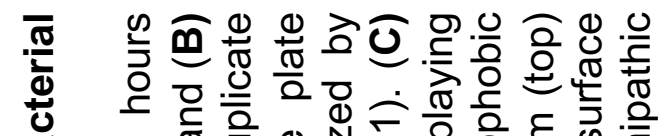 N 능 4 क

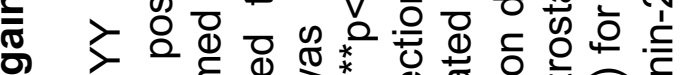

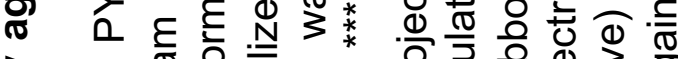

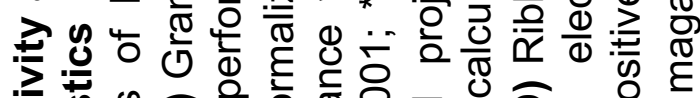

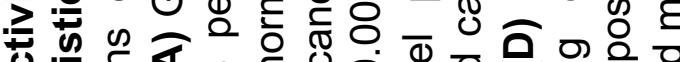

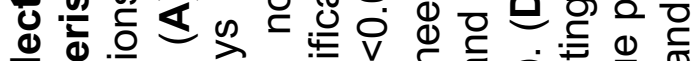

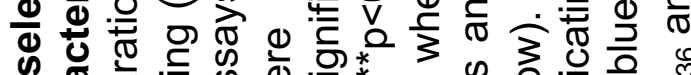 क

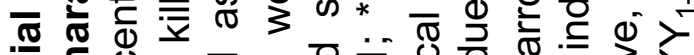

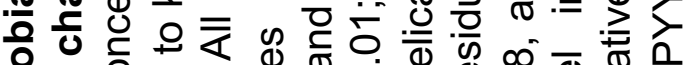 × . है

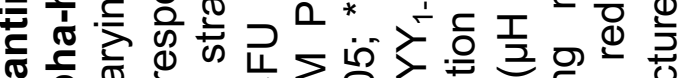

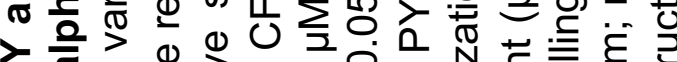 خ ง 守 ๑ थ क ल

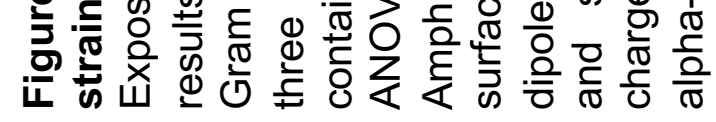

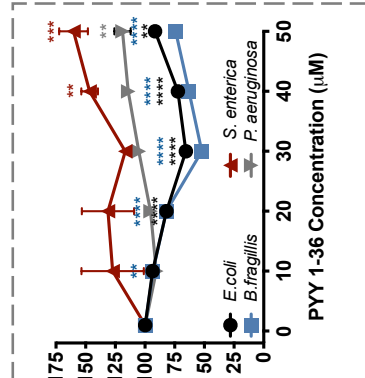

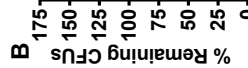

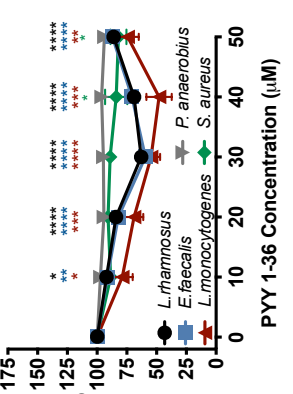

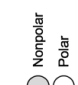

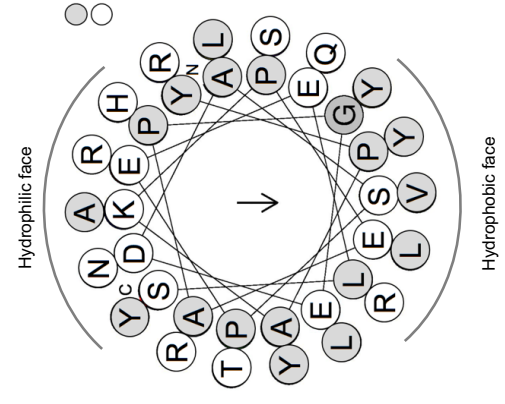

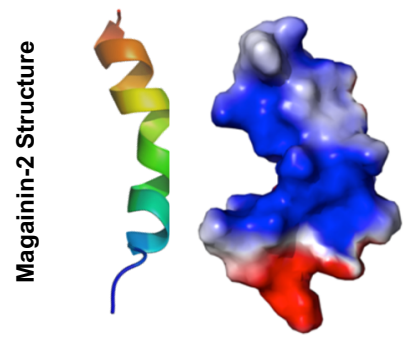

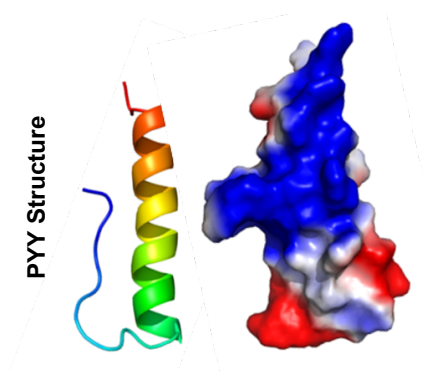




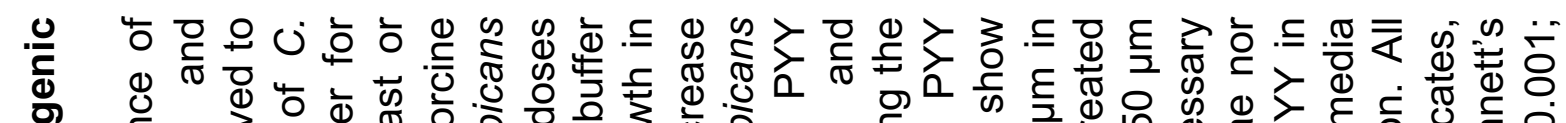

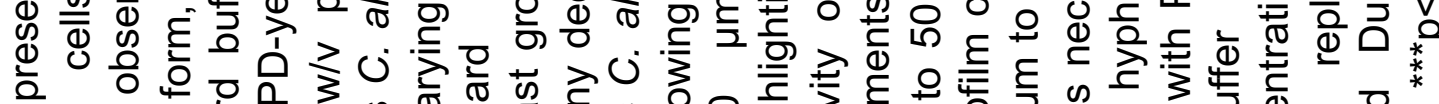

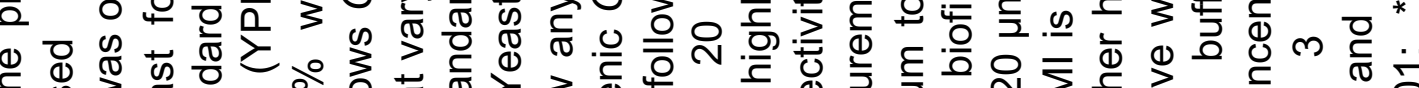

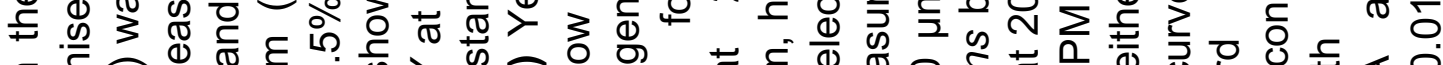

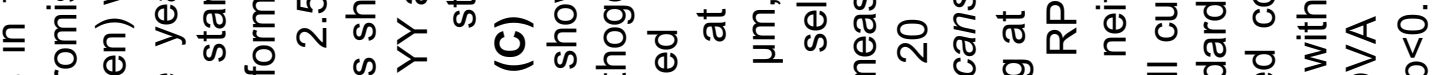

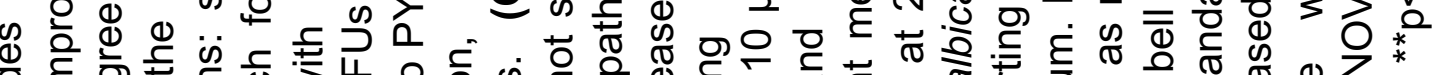

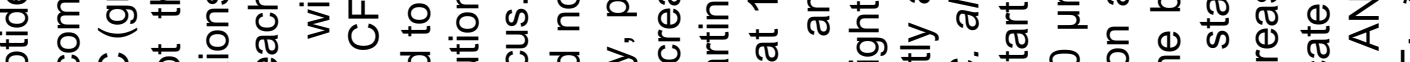

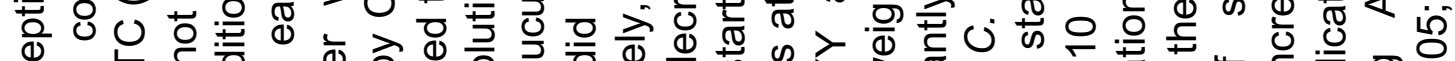
ฉ

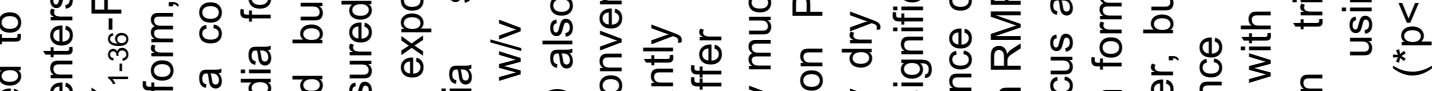

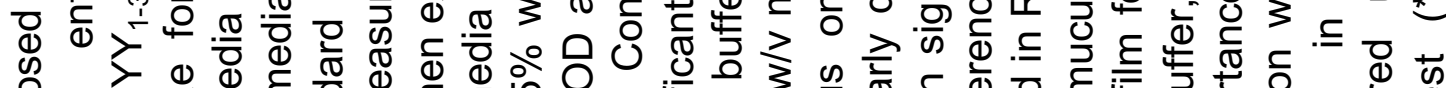
象

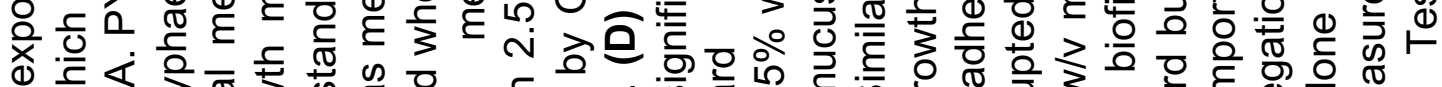

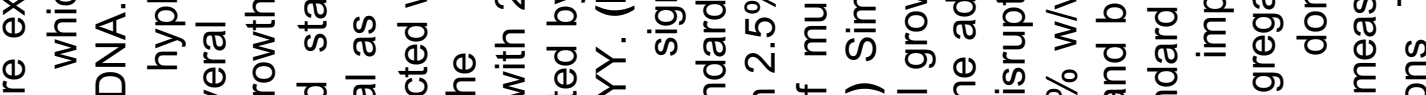
তু

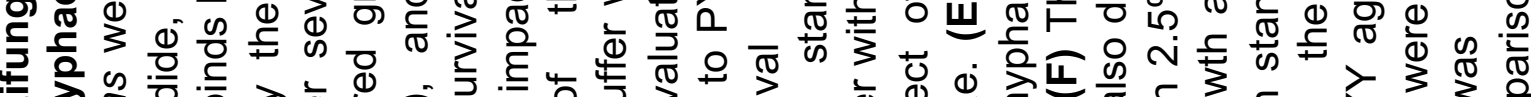

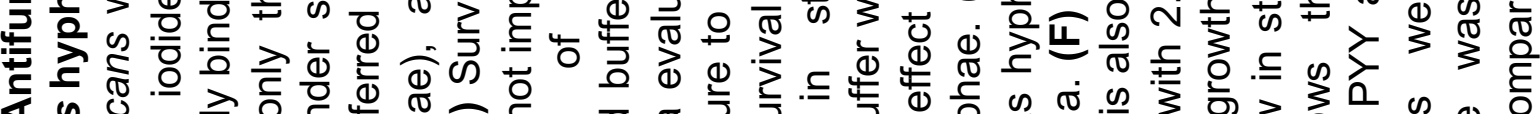

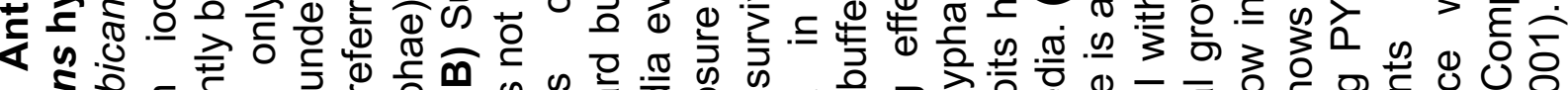

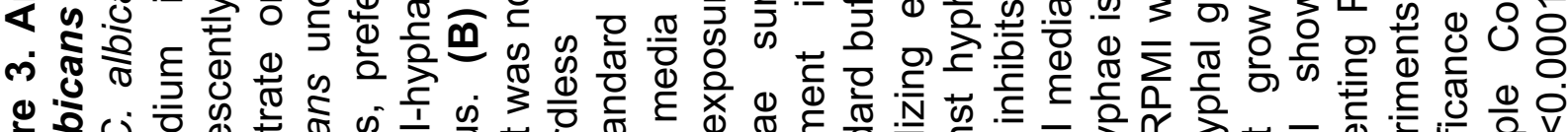

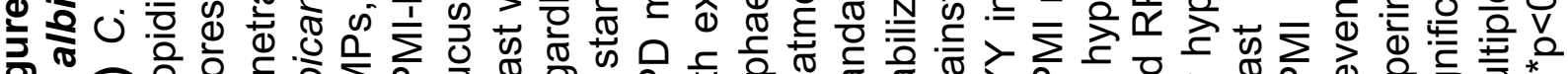

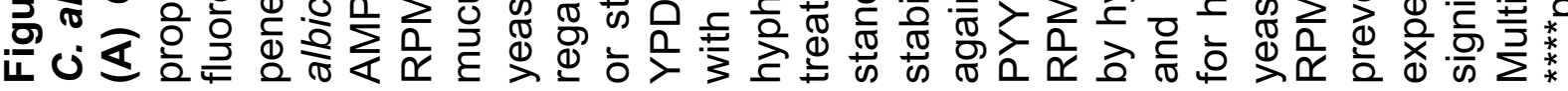

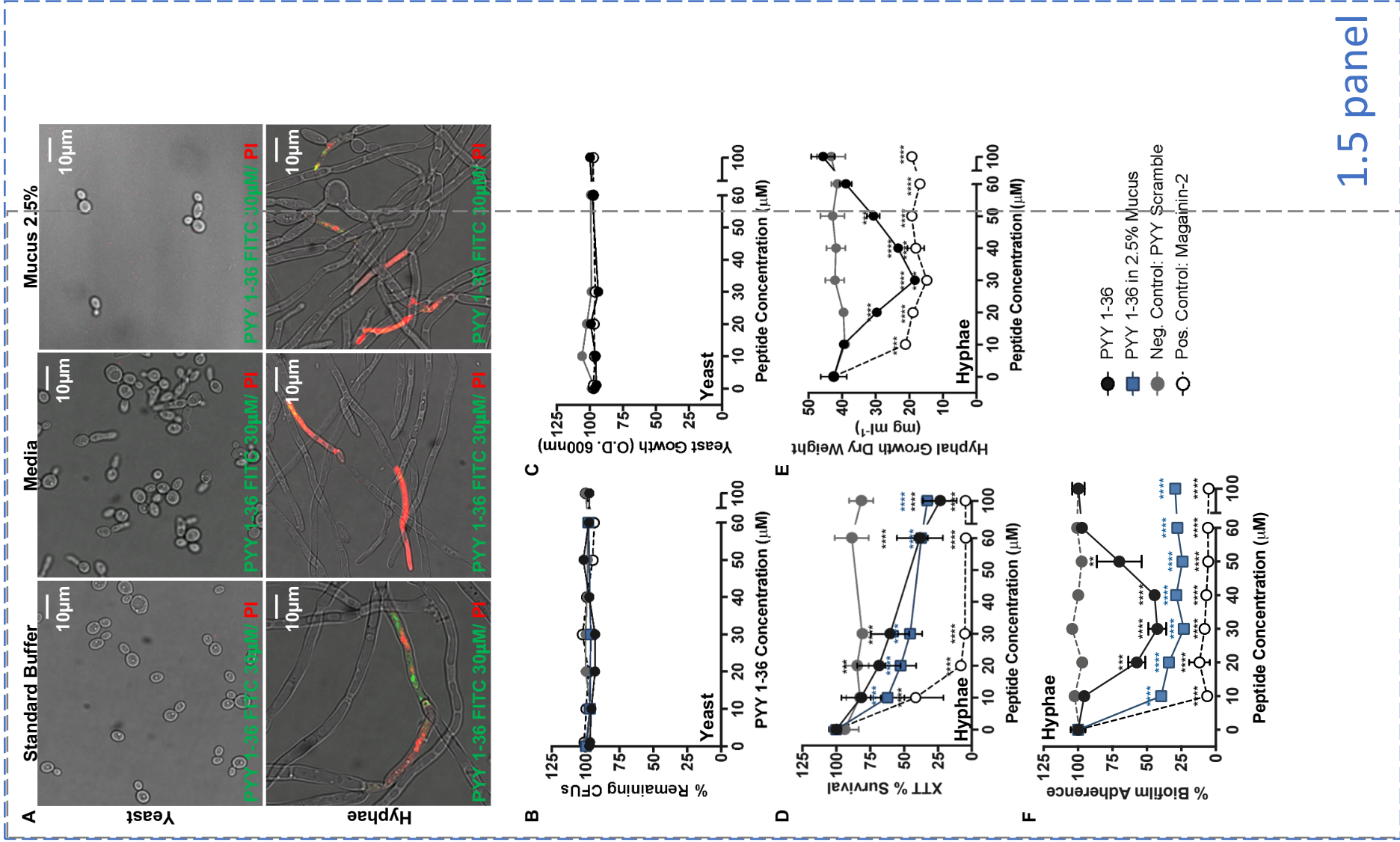




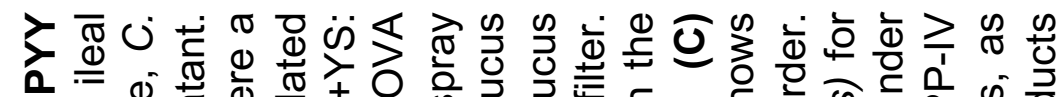

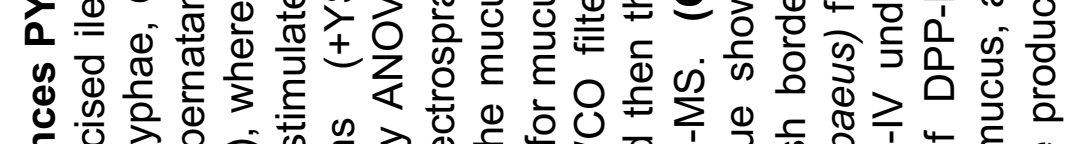

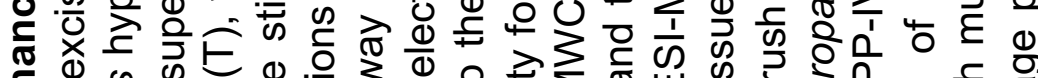

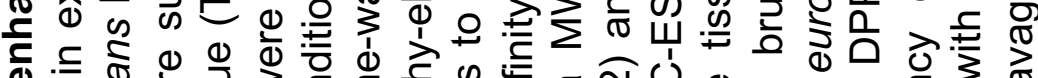

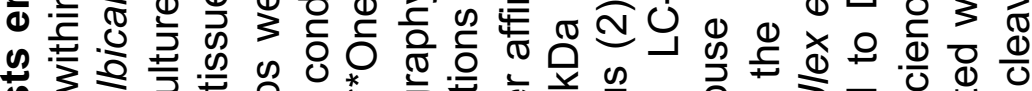

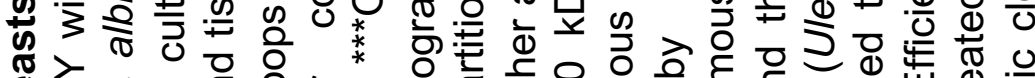

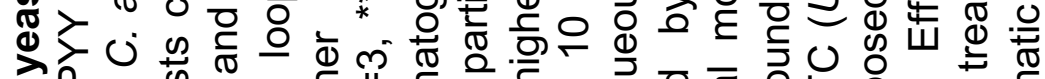

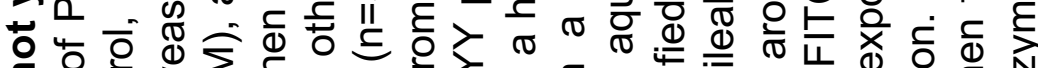

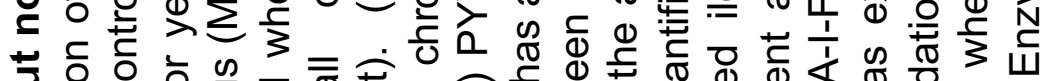

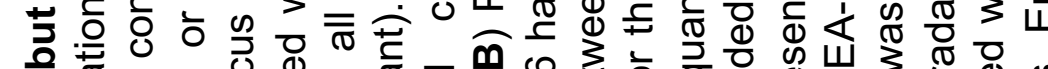

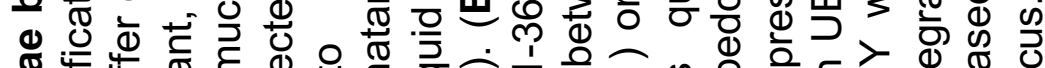

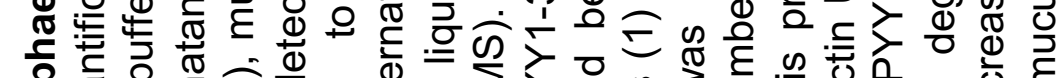

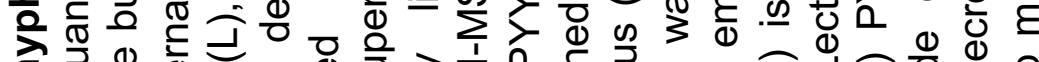

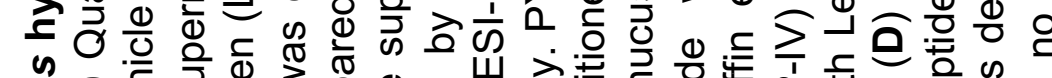

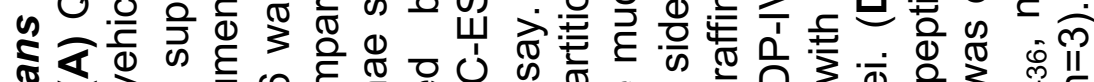
đ广 누의

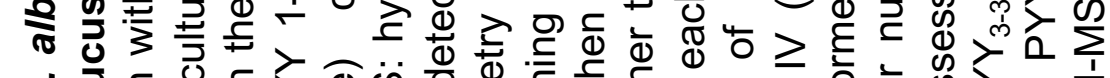

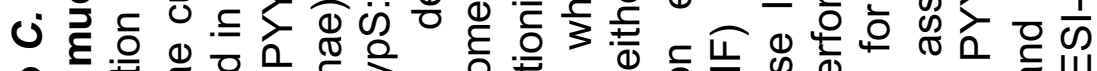
$\circ$ 은 o

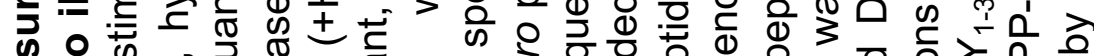

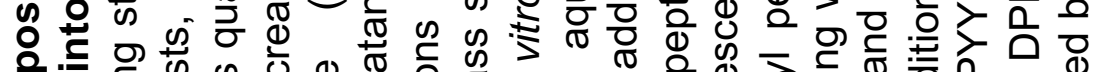

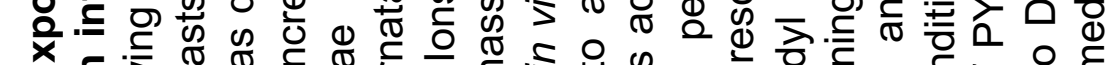

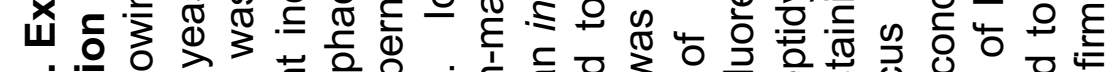
ம

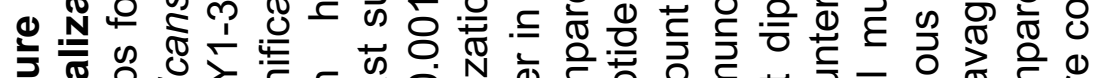

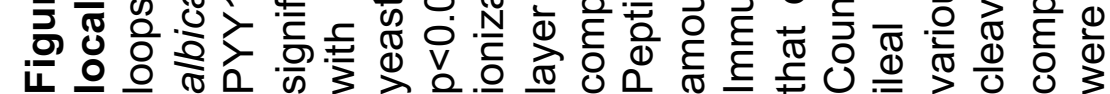

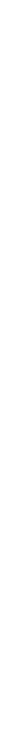




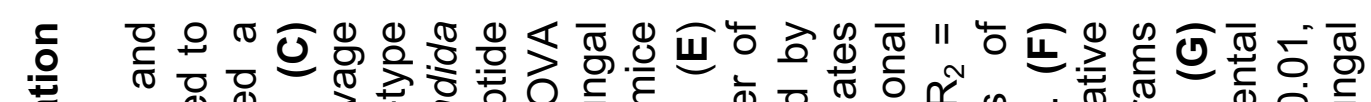

ब

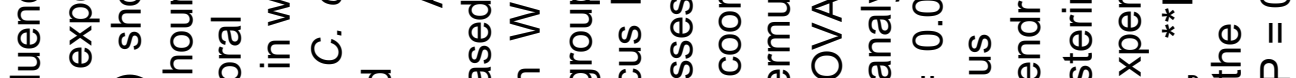

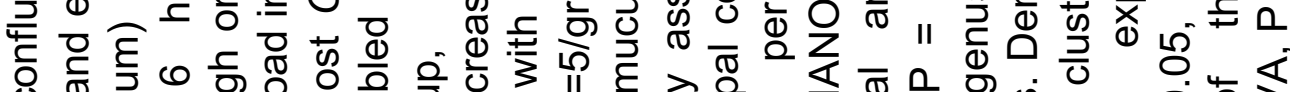

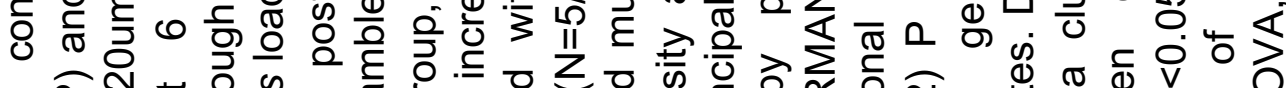

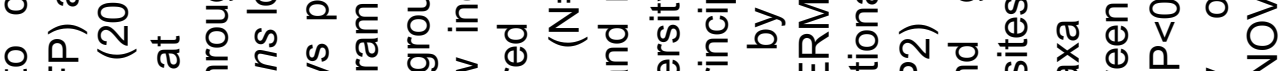
+

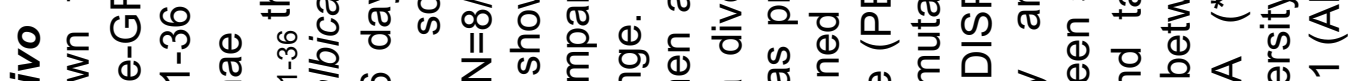

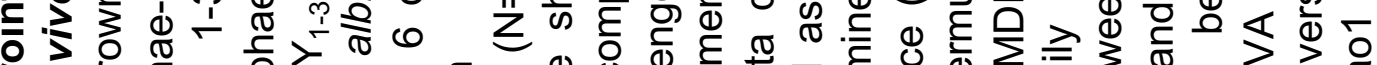

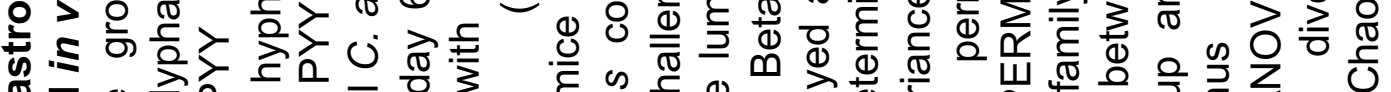

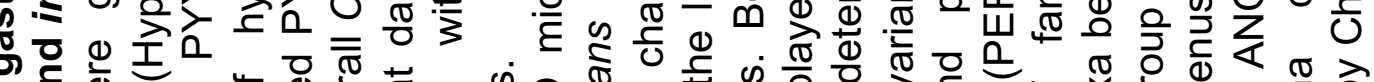
क 木 $\frac{\omega}{3}$ क

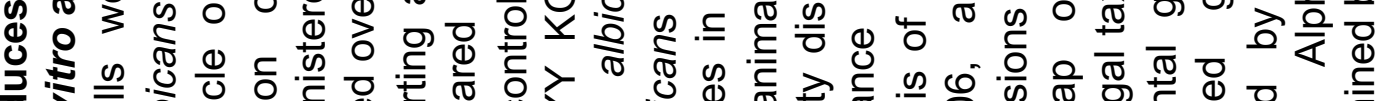
才 $\overline{0}$

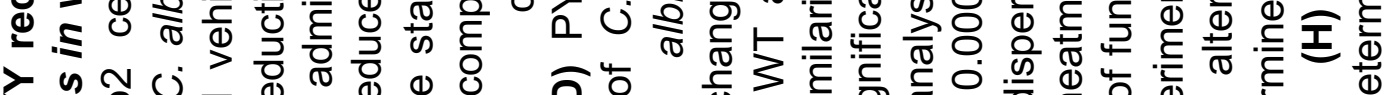
خ 口 0 ט

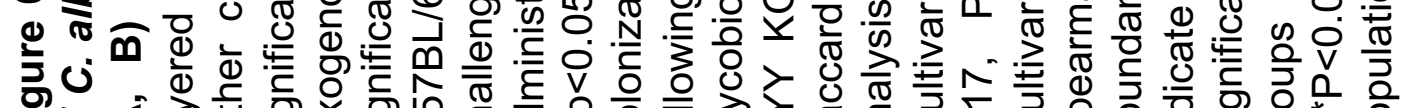

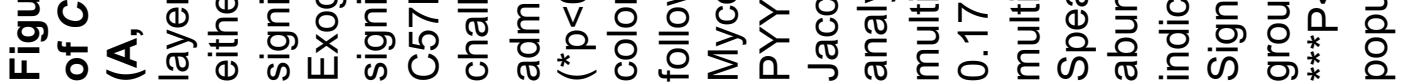
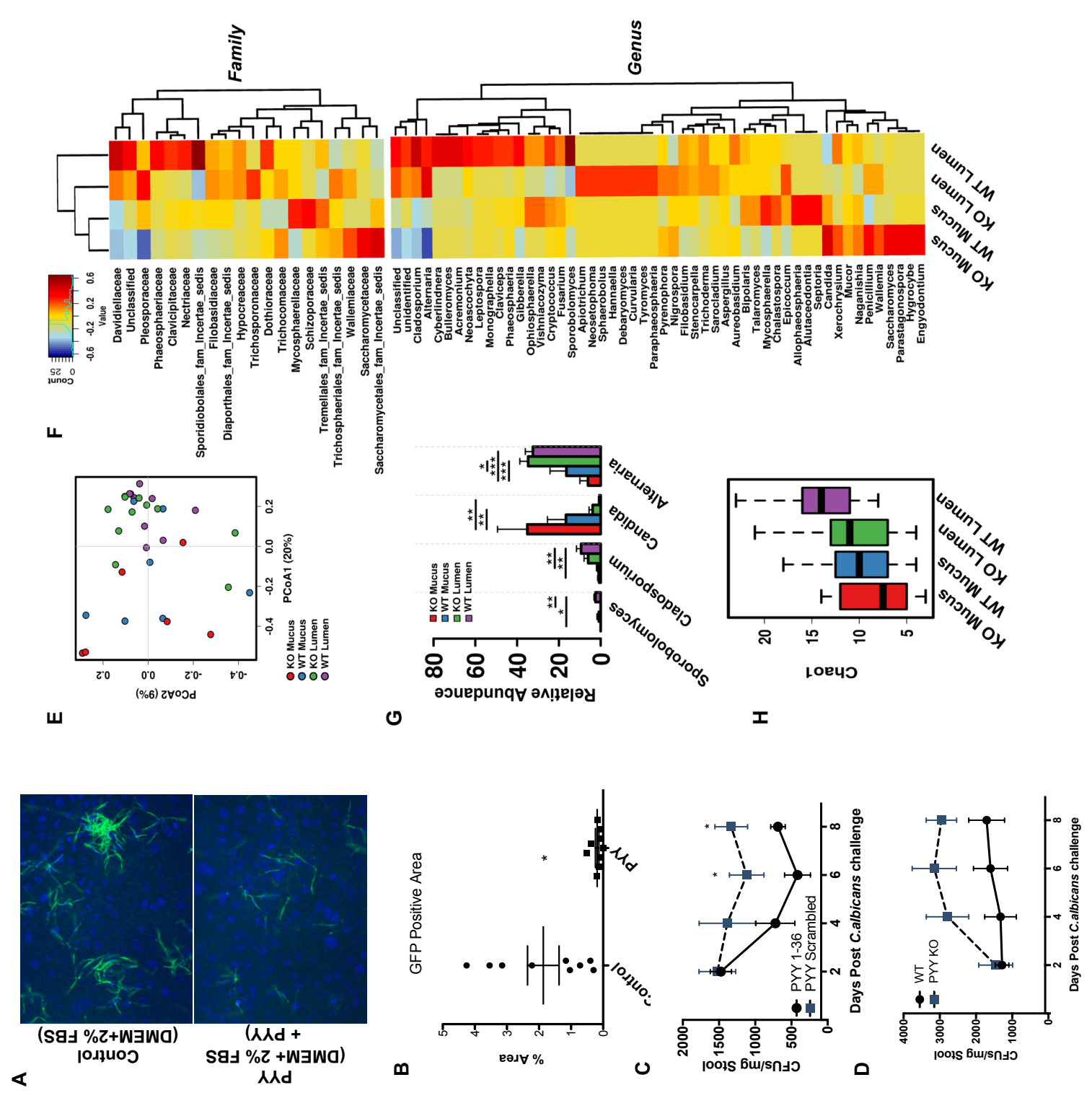


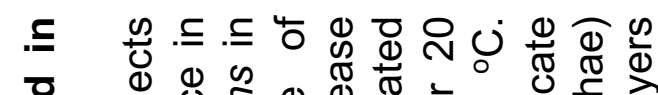

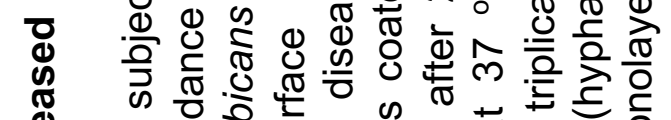

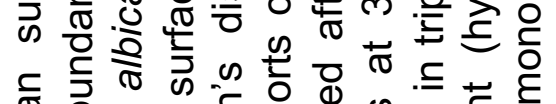
๙ ह

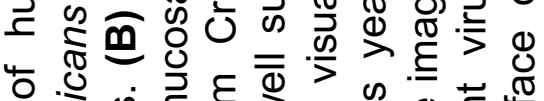

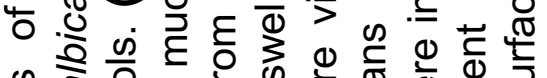
क ते

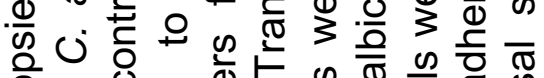
음 웅뉴

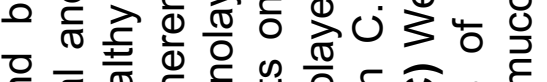

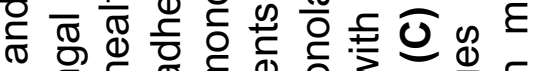
ฯ

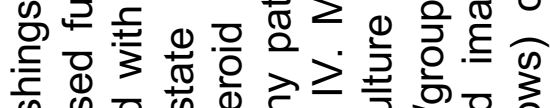
员

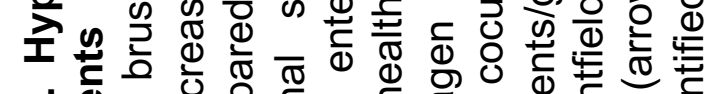
$\infty$.

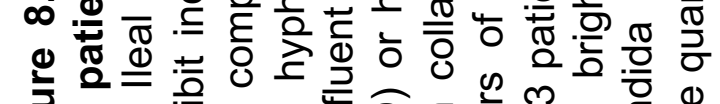

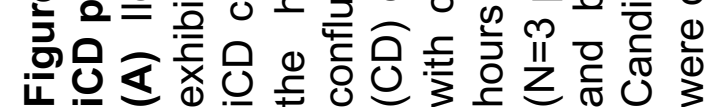

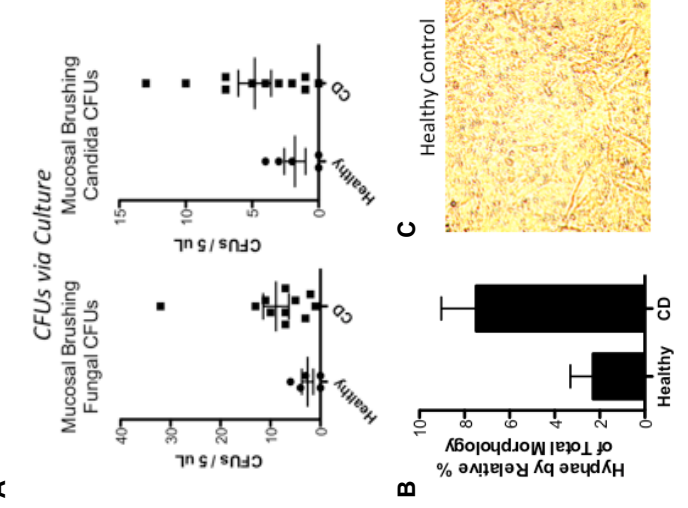




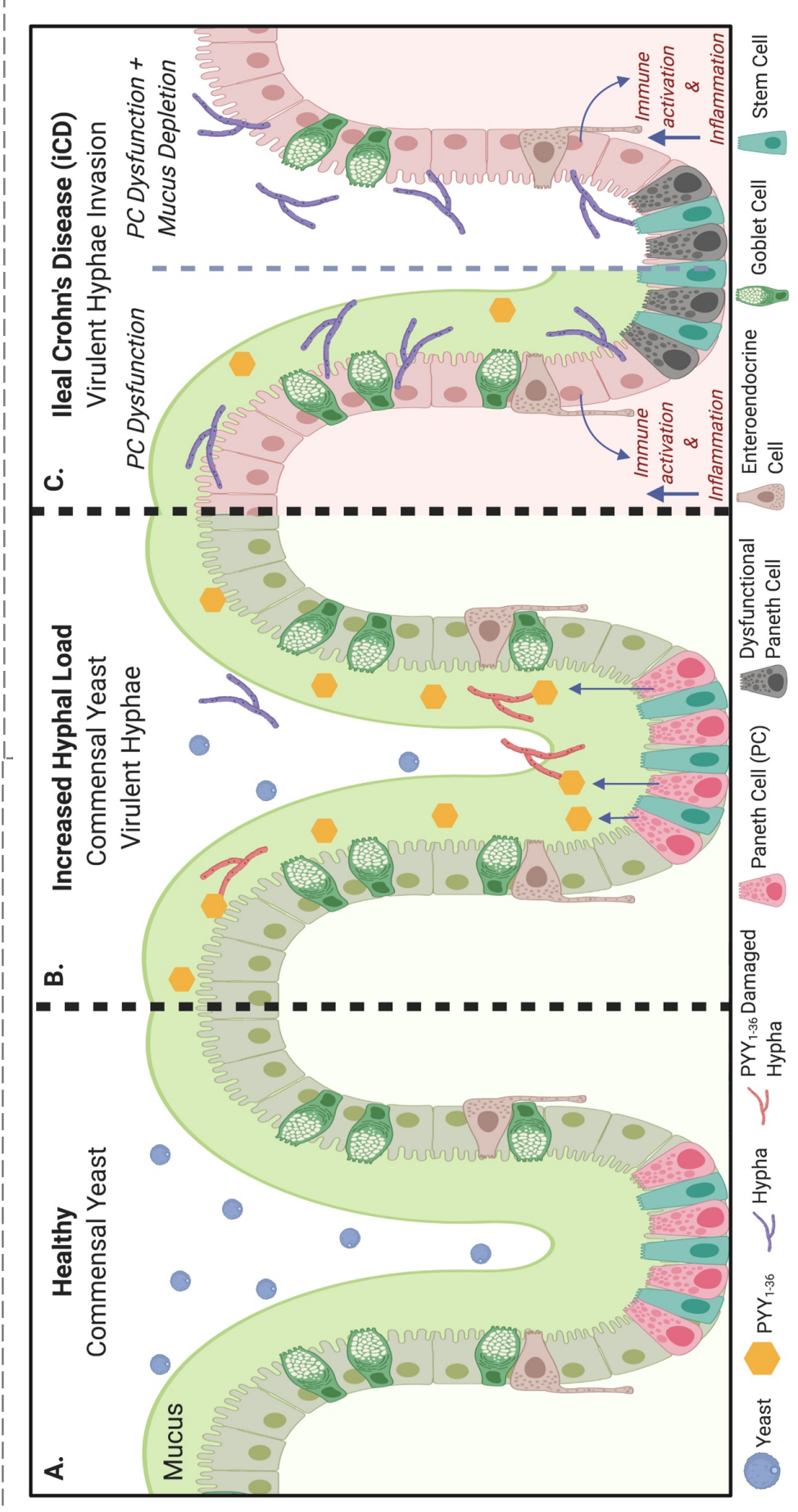

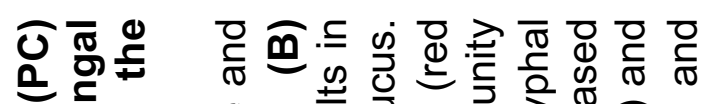
$=\underline{\underline{1}}=\frac{0}{0}$ i

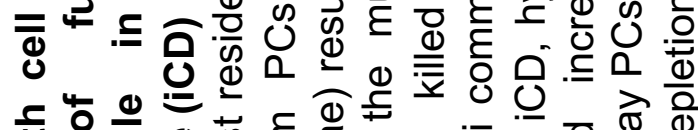

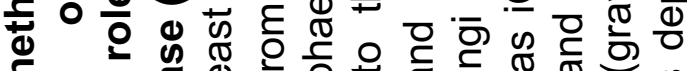
त

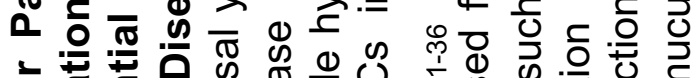

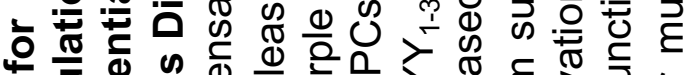
可范

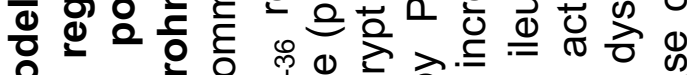

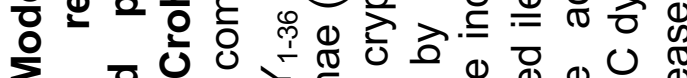
은 宁

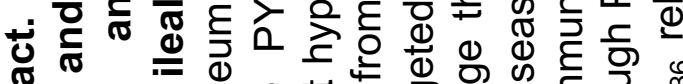
車

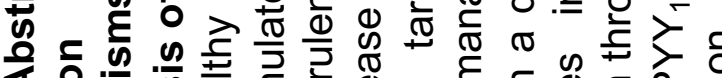

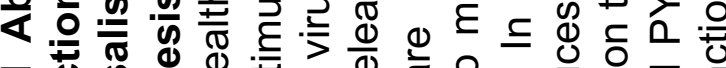
历ั

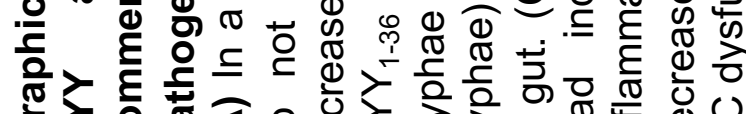

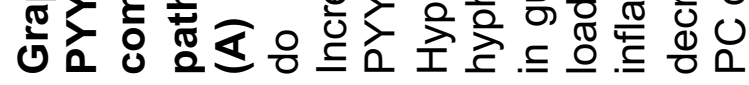




$$
\begin{aligned}
& \text { 选 } \\
& \text { 짐 } \\
& \text { के }
\end{aligned}
$$



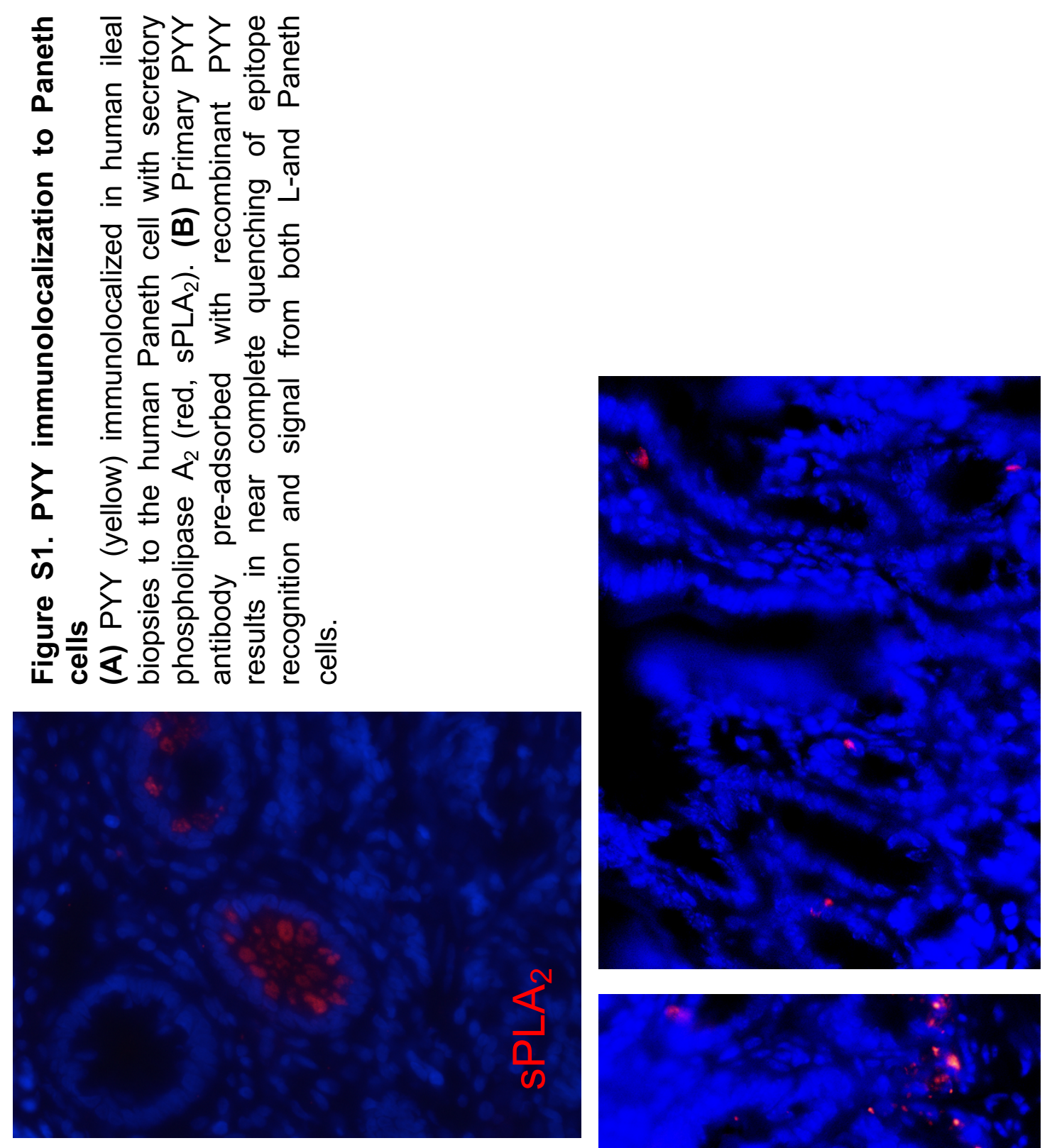

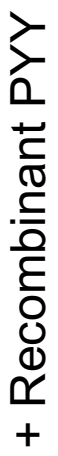
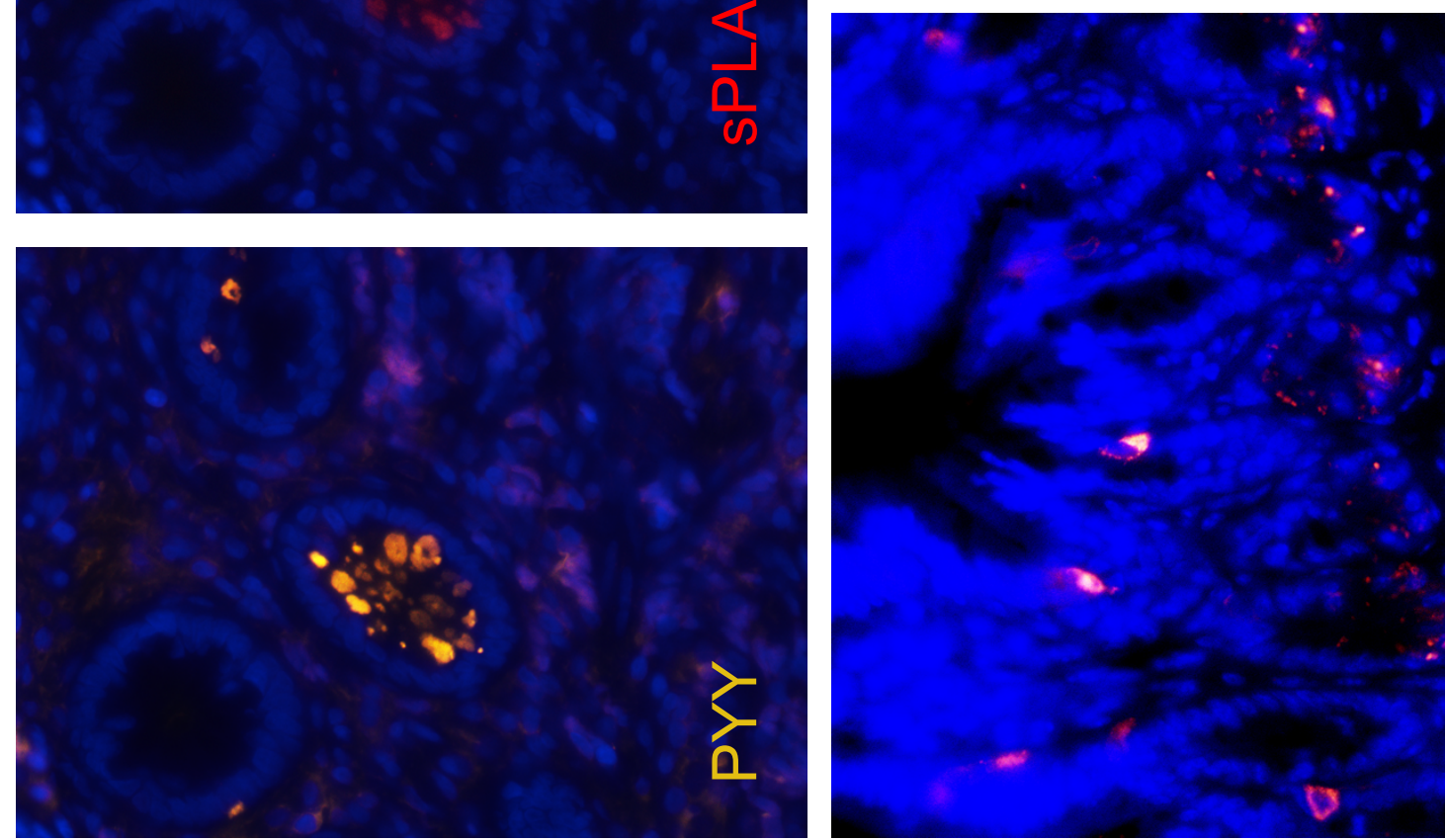

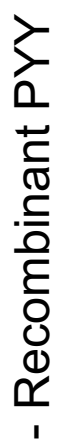

$\varangle$ 


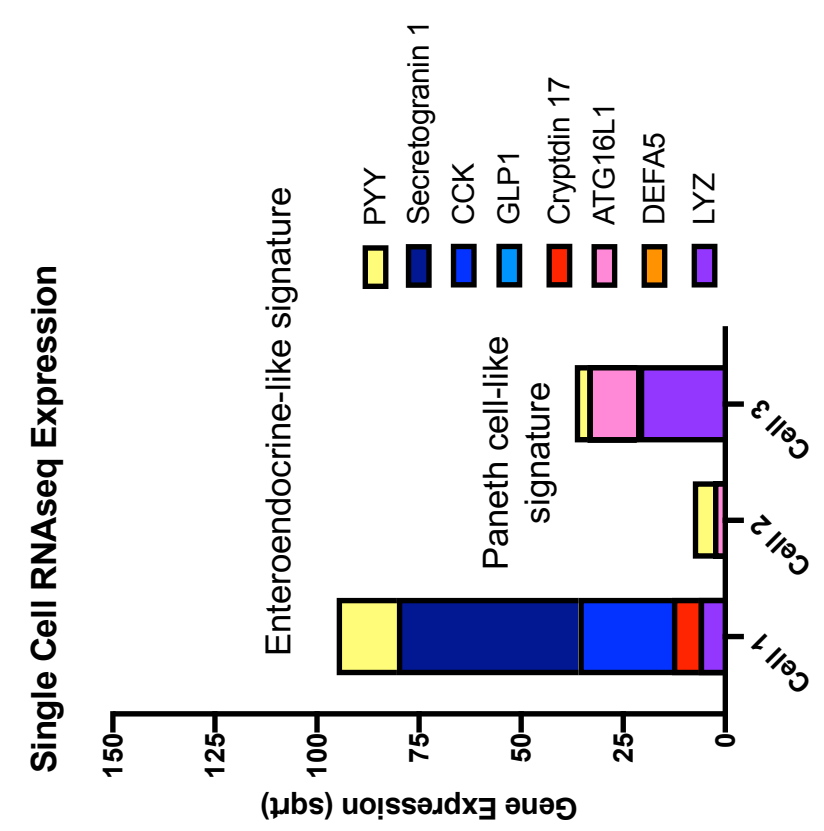

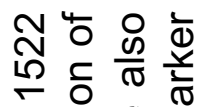
อิ 음 文㐫 중 o

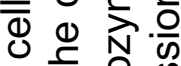

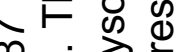
伭京

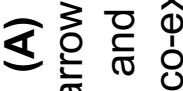

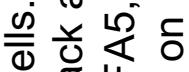

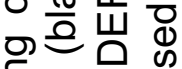
든 क. 인

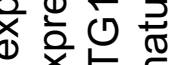

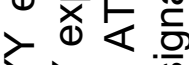
¿ゔ (1) 늫 흥ㅎㅁ $\div$ 옹 需 웡 $\circ$ क ⿻ ㇒ 응 을 은 Nㅡㄴ 응 응 今

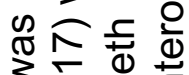
उᄃ

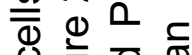
U

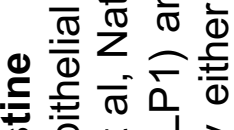

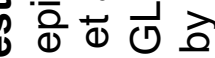

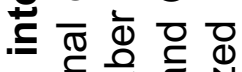
元言 更 过 क $\leqq$.

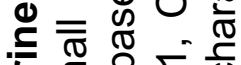
के क्ष ऽ त 는 논 ष $\varepsilon$ ए 这 作 番 $\frac{\pi}{\pi} \overline{0}$

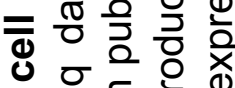

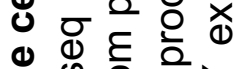
훈인 的曲 $\underline{\bar{D}}$

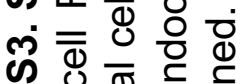

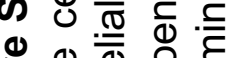
产产焉

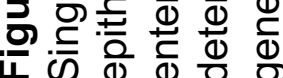




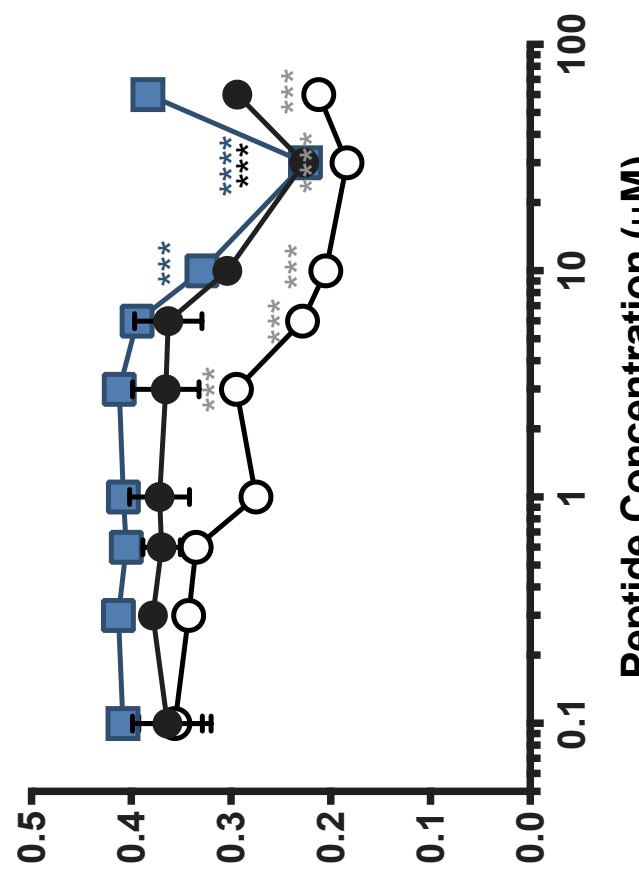

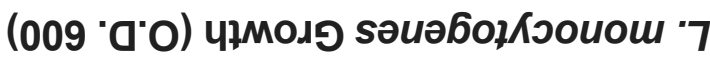

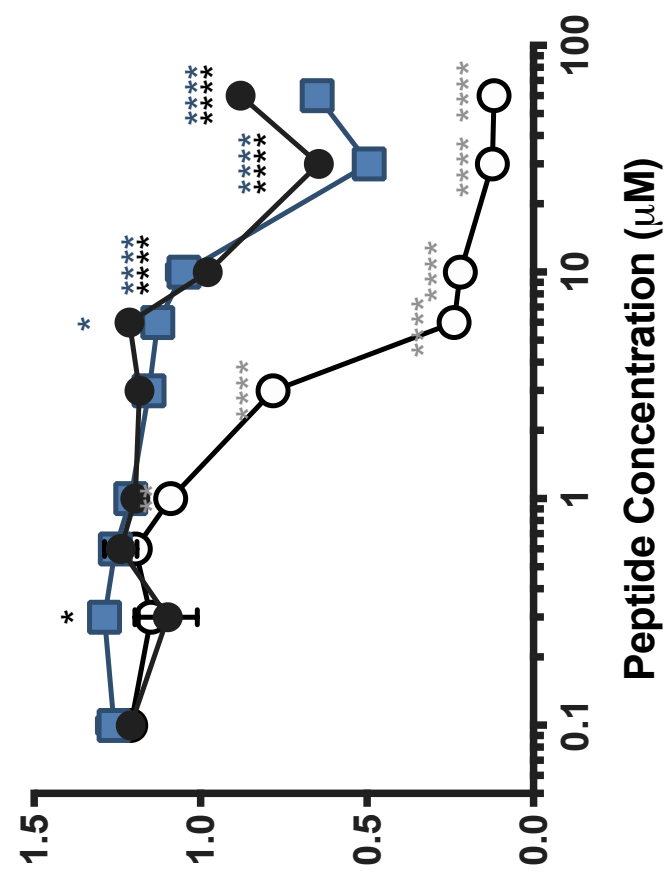

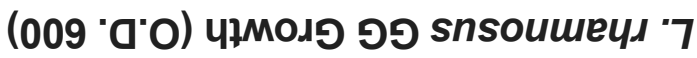

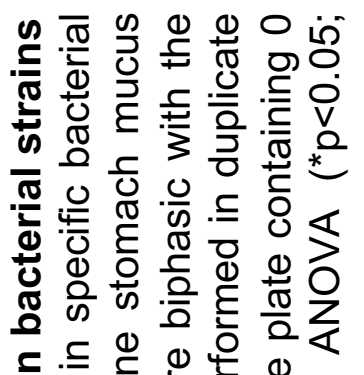

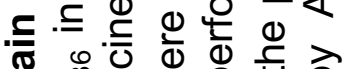

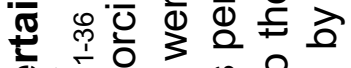
인 $4 \div \geq$ D

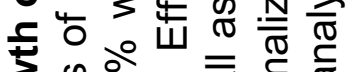
วิ 는 는

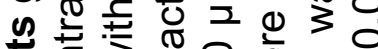

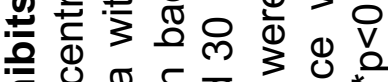

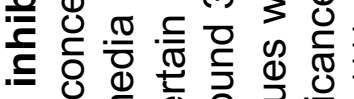
完

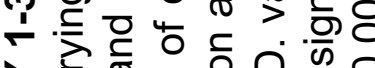

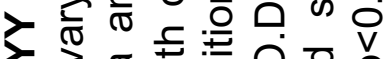

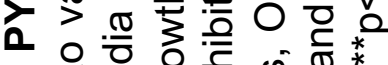

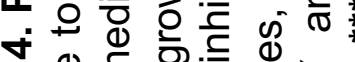
फे

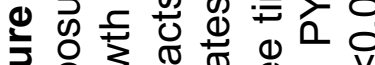
亏ํำ

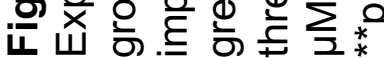
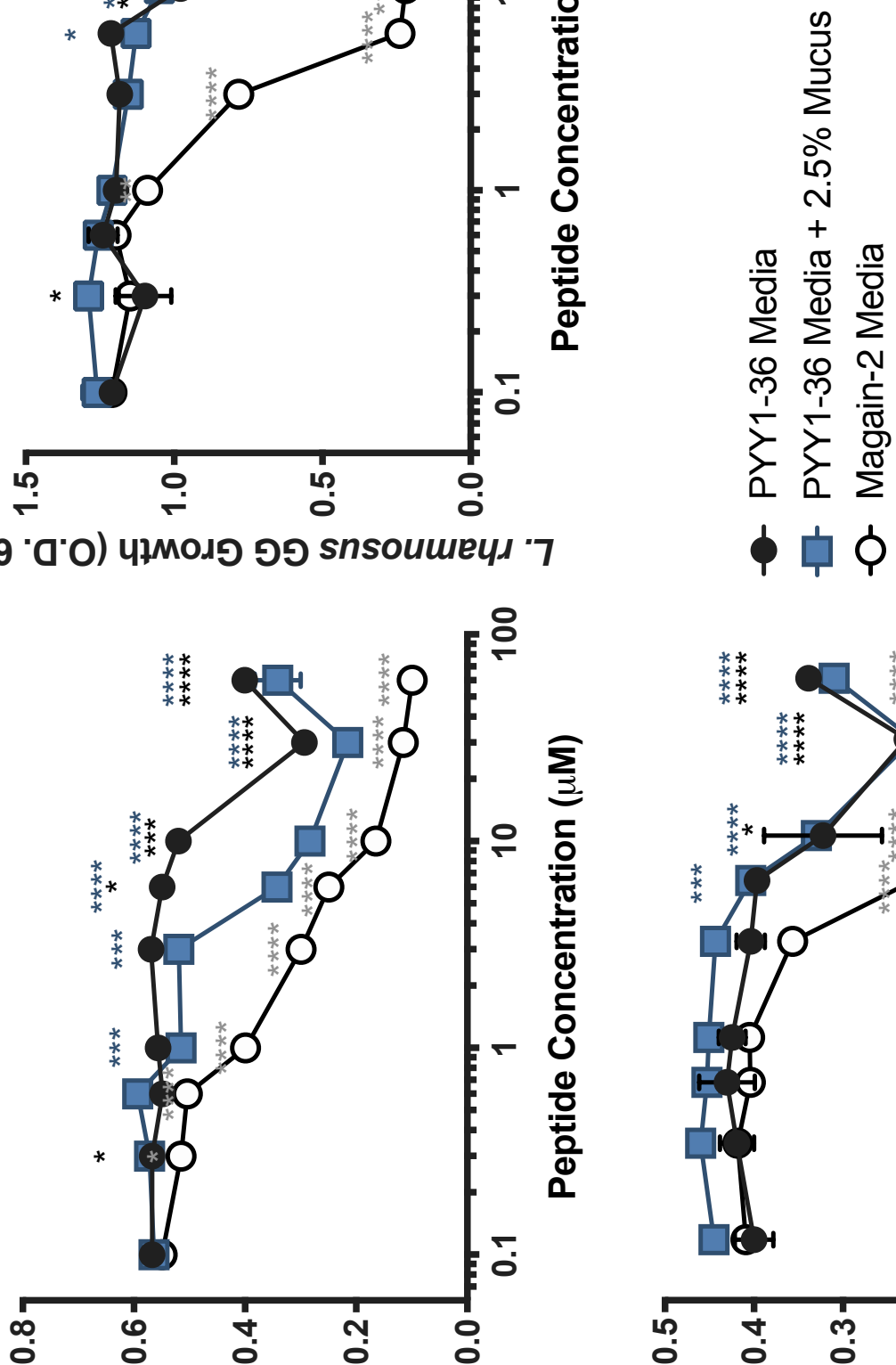

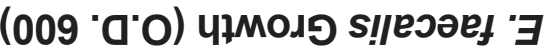

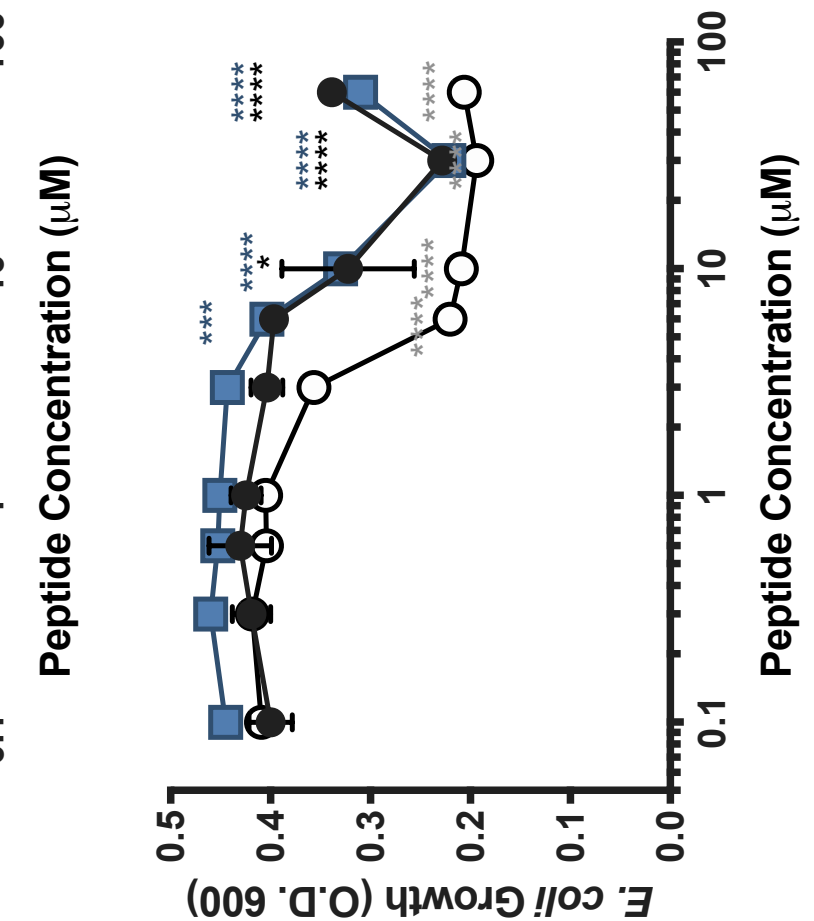




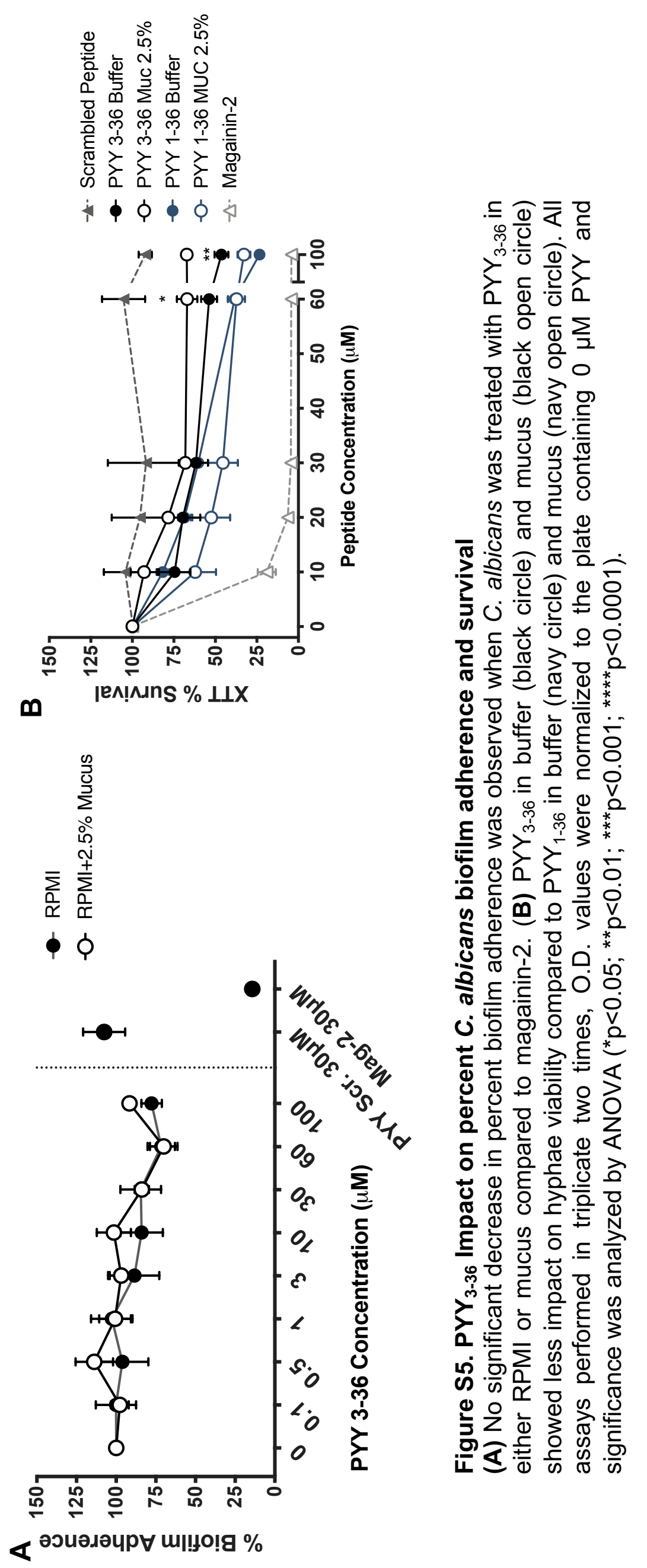




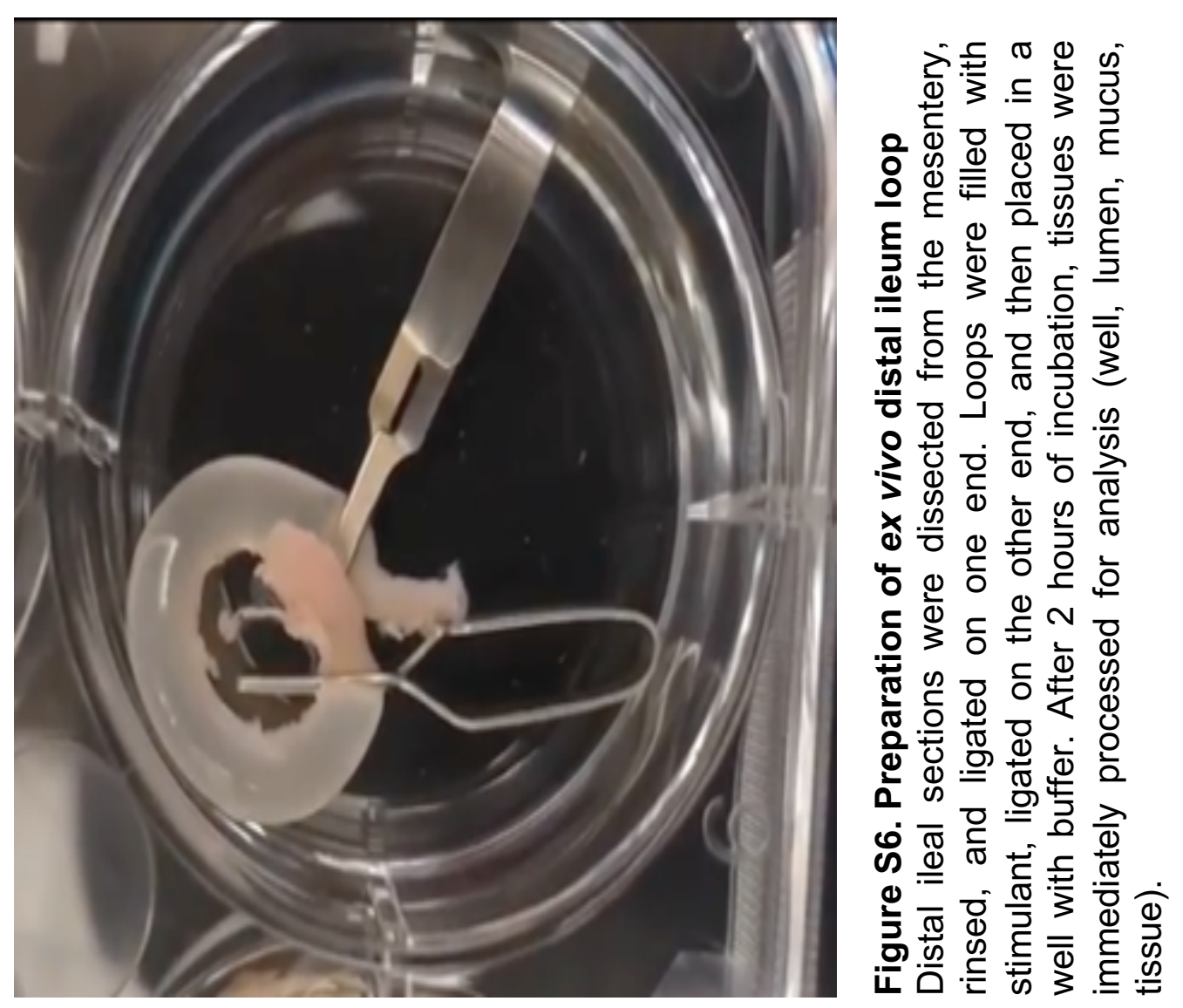




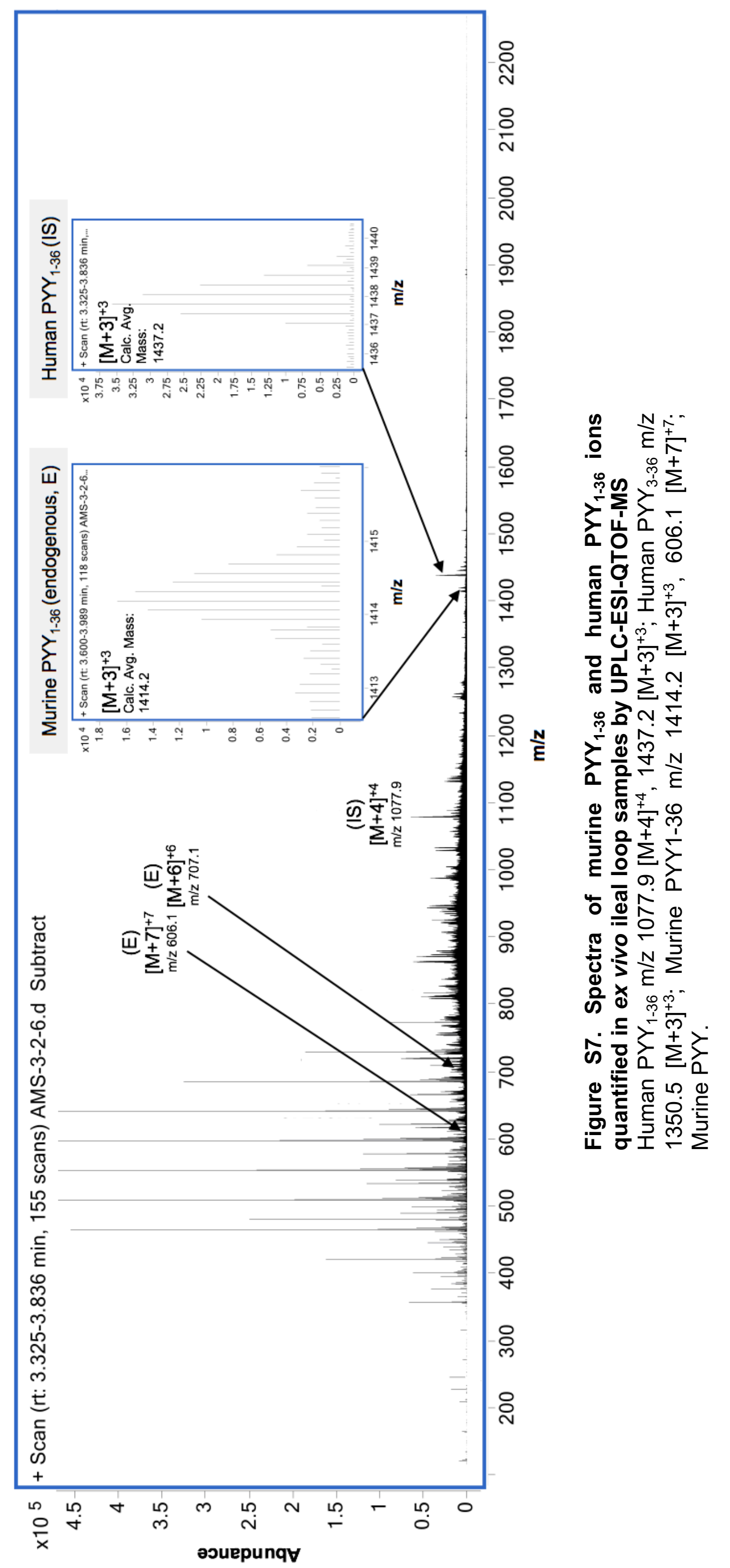




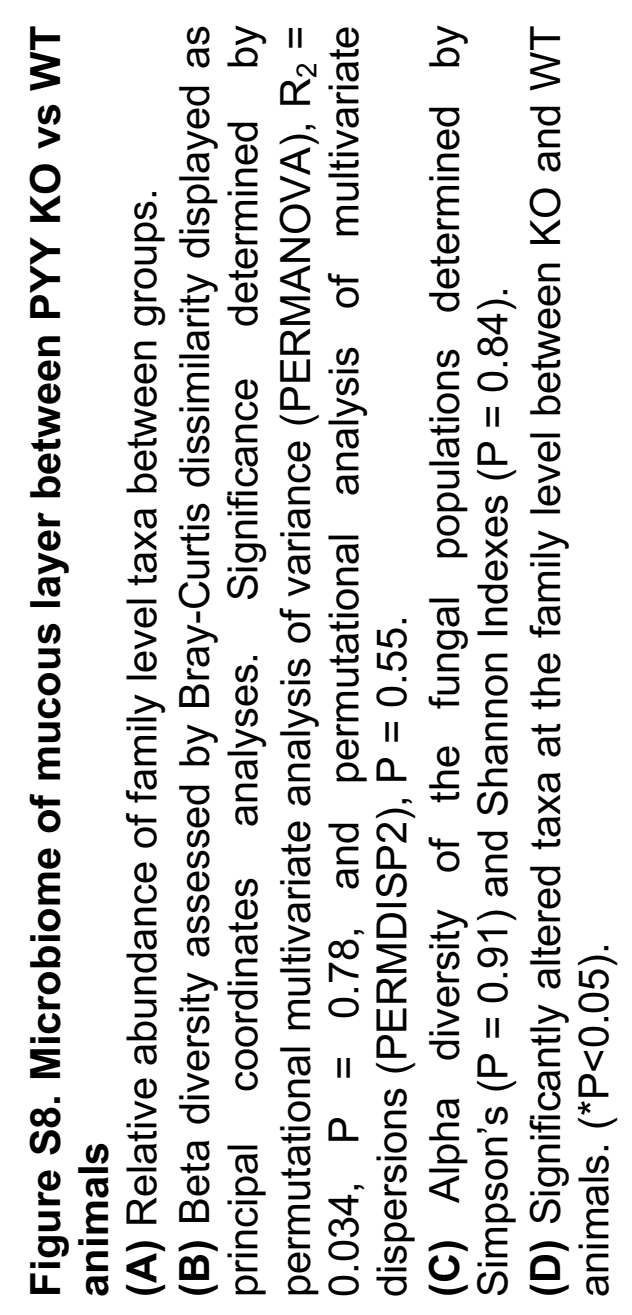

$\infty$

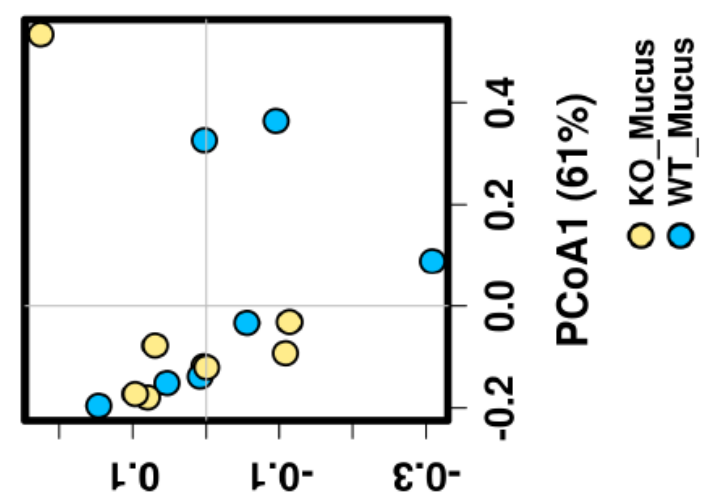

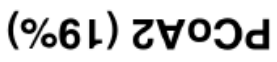
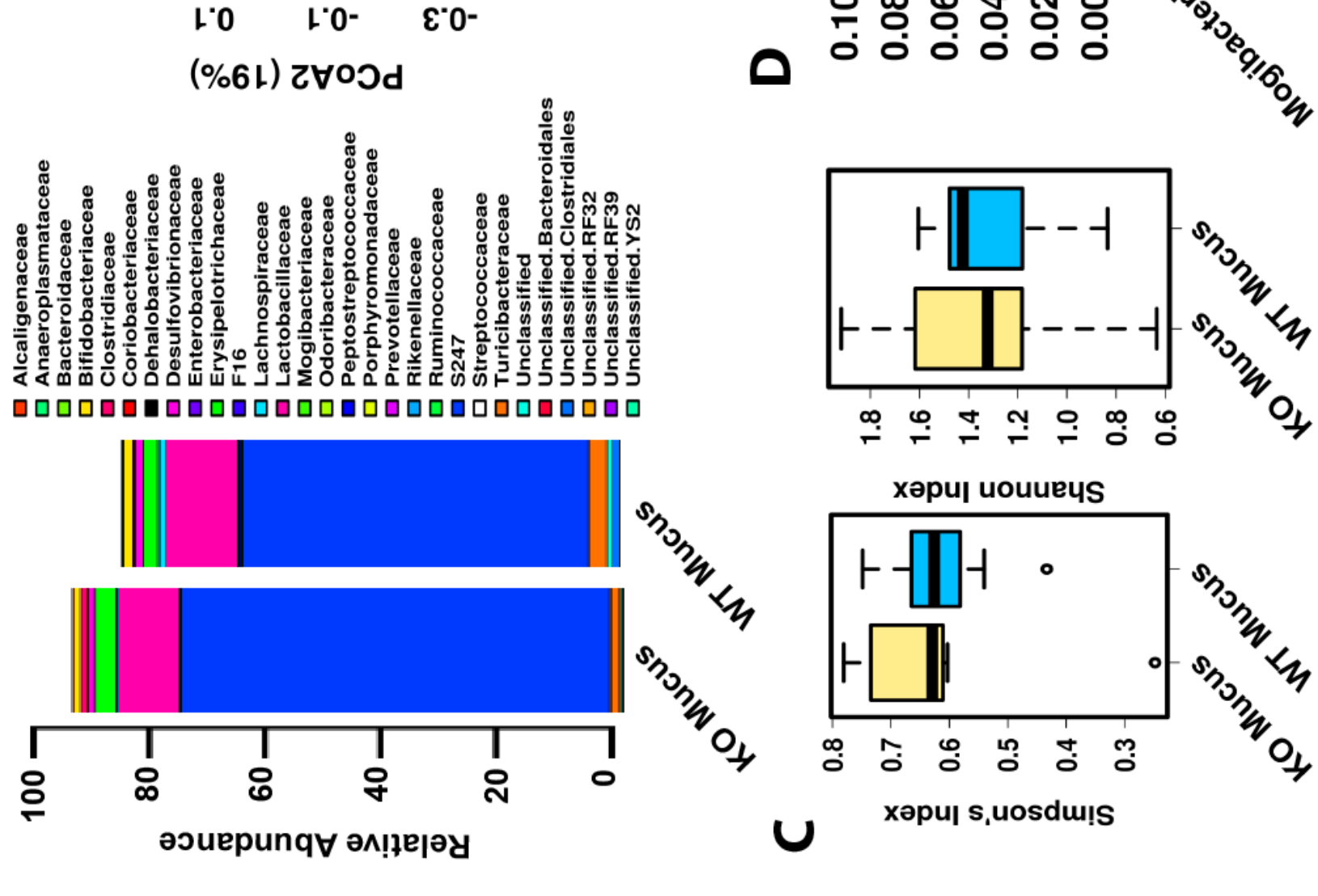